SAND81-0786

Unlimited Release

RPARD C.Y.

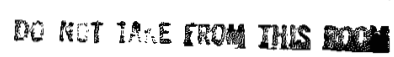

HIGH TEMPERATURE ELECTRICAL CONDUCTIVITY AND THERMAL DECOMPOSITION OF PHENOLIC- AND SILICONBASED DIELECTRICS FOR FIRESET HOUSINGS

R. T. Johnson, Jr. \& R. M. Biefeld

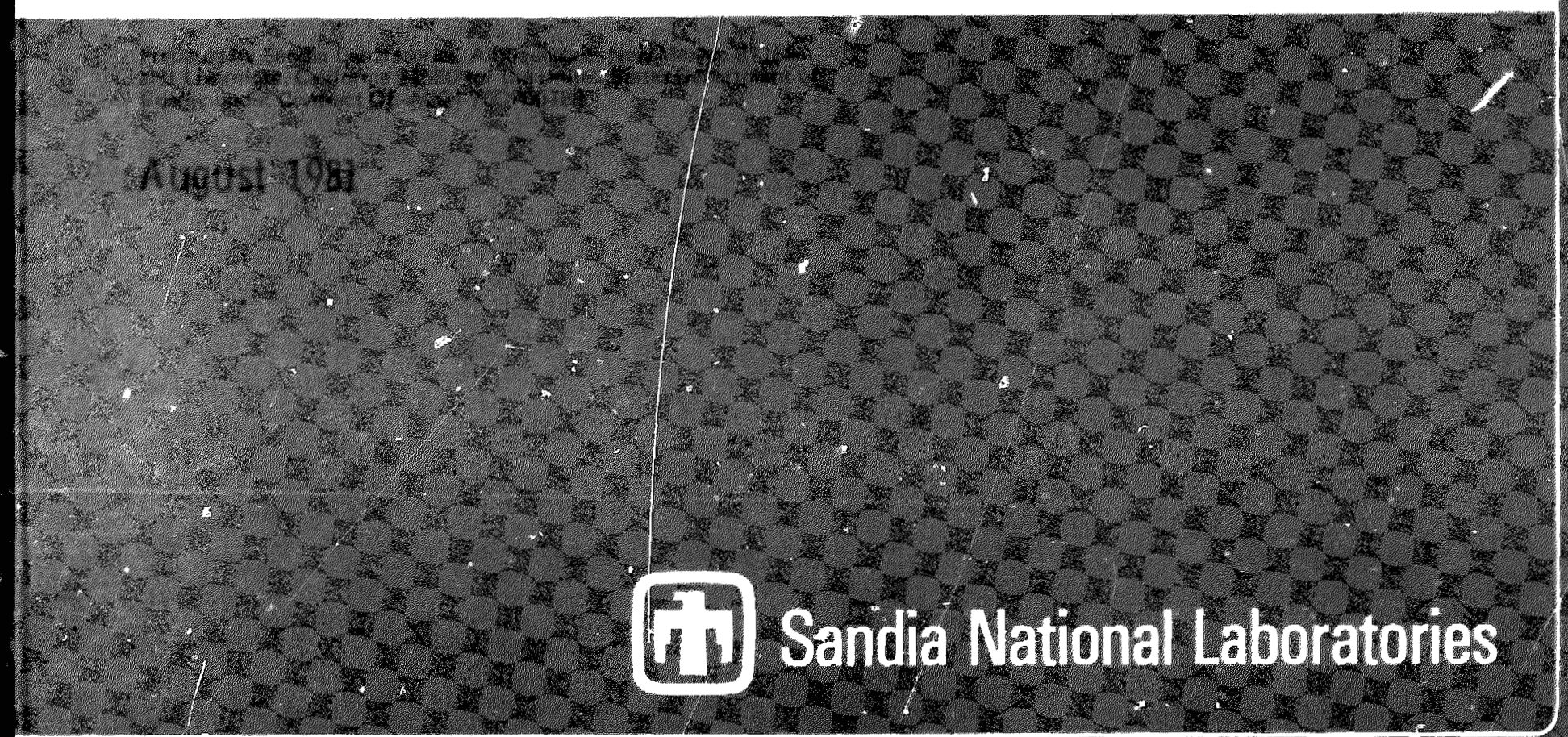




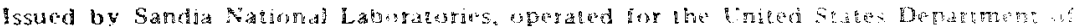
Energy by Sandia Corpuriatiout.

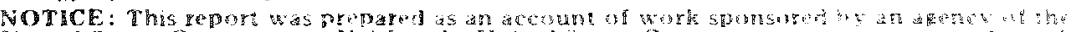

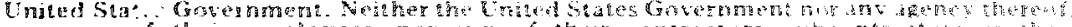

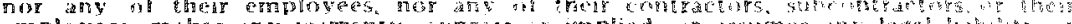

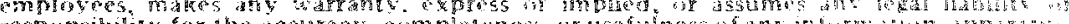

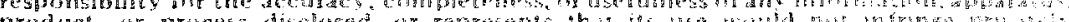

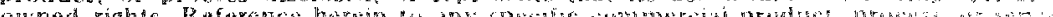

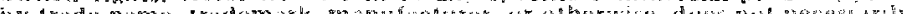

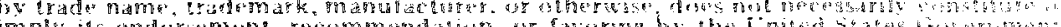
any

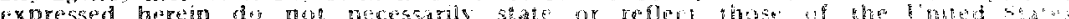

Go

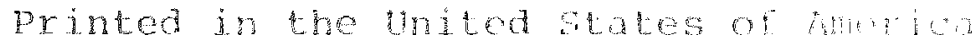

Availabla Erom:

National Techical Information Service

U. S. Department of Commerco

5285 Port Roval Roa

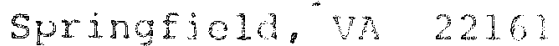

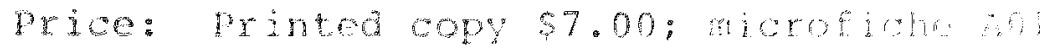


SAND81-0786

UnIimited Release

\title{
HIGH TEMPERATURE ELECTRICAL CONDUCTIVITY AND THERIAL DECOMPOSITION OF PHENOLIC- AND SILICONE-BASED DIELECTRICS FOR FIRESET HOUSINGS
}

\author{
R. T. Johnson, Jr. and R. M. Biefeld \\ Sandia National Laboratories \\ Albuquerque, New Mexico 87185
}

\begin{abstract}
The temperature dependence of the electrical conductivity and thermal decomposition characteristics of several phenolicand silicone-based materials of interest for Eireset case housings have been measured to $600-700^{\circ} \mathrm{C}$. The materials are phenolic or silicone resins reinforced with glass chopped fatro or oth. The conductivity temperature dependence was meacured during decomposition in a nitrogen atmosphere at a heating rate of $10^{\circ} \mathrm{C} / \mathrm{minute.} \mathrm{Applied} \mathrm{electic} \mathrm{fields} \mathrm{were} \mathrm{from} 4 \% 10^{2}$ to $4 \times 10^{3}$ volts/cm. Thermal decomposition characteristics were investigated by mass spectroscopy in vacuum and thermal gravimetric andysis in nitrogen and air. Nearly ohmic voltagecurrent characteristics were obtained, except where decompastion and/or outgassing was pronounced. For the silicone materels, the conductivity increases nearly monotonjcally with increas

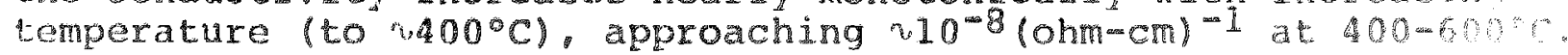
The phenolics exhibic conductivity peaks at $250^{\circ} \mathrm{C}$ and $400^{\circ} \mathrm{C}$. The peak magnisudes Imaximum value $33 \times 10^{-8}$ (ohmmem) 1 ind positions depend upon the material formulation age are post cure conditions. Postcuring to $250^{\circ} \mathrm{C}$ for $1 \mathrm{~h}$ eliminetes the conductivity peak at $250^{\circ} \mathrm{C}$. The semperature dependence of the mass 105 and decomposition products correlates with pronoury. changes (peaks) in electrical conductivity. Results show that the silicone materials have better thermal stability and are better high temperature electrical insulators than the phenolic materials. Furthermore, the excellent correiation obtained between thermal and electrical properties suggests thet $6160 \mathrm{cos}$ conductivity can be used as a thermal analytical tool in characteriaing these materals.
\end{abstract}


TABLE OF CONEENTS

\section{Page No.}

INTRODUCTION

MATERIALS

6

Phenolic Materials

6

Silicone laterials

7

EXPERIMENTAL WETHOD

9

Electrical Measurement Technigues

Thermal Analysis Techniques

ELECTRICAL RESULTS

Phenolic Materials

Silicone Materials

THERMAL RESULTS

COREELATON OF ELECTRTCAL RND THERMAL RESUITS

CONCLUSIONS

ACKMOWLEOGEMENTS

REFERENCES

APPENDIX A: FOUR TERMIMAL CONDUCYUITY EXPERIMEMTS 57

APPENDIX B: MASS SPECTRA RESULTS

61 
TABIE OF CONTENTS

Page No.

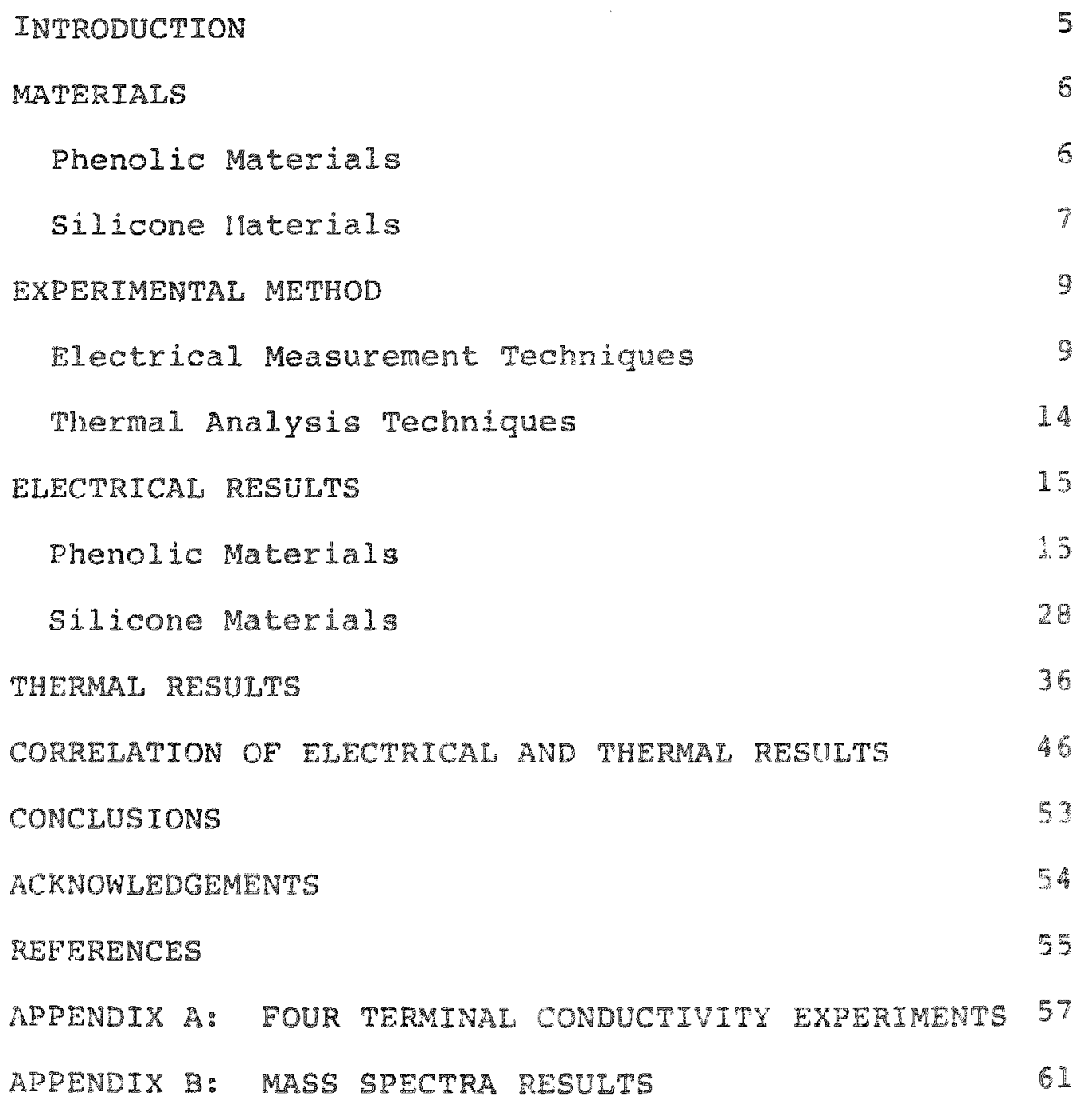




\section{INTRODUCTION}

Nuclear safety concerns over the possibility that a weapor may be subjected to an accident involving a fuel fire and that a high voltage source may be present indicated the need for information about the high temperature electrical insulating characteristics of fireset case materials. The materials of interest included those based on phenolic and silicone resins reinforced with glass chopped fabric or cloth wich could be molded or formed into complex shapes suitable for fireset case housings.

There is very little information in the literature on th nigh temperature electrical properties of these materials. data are available on changes in the dielectric properting resins during the curing process (to temperatures of $2100 \mathrm{C}$ 11-41, and on the properties of pyrolyzed polymers metwr obtained after pyrolysis to temperatures $\left.400^{\circ} \mathrm{C}\right)\left(5-10 \|^{\circ}\right.$ ixcept for limited data on other materials [11]. there is practically no information atalible on changes in electral conduction chatacterigtics during the decomposition process [12.13] as the temperature is increased to $600-700^{\circ} \mathrm{C}$. The purpose of the studies reported herein was to obtain suit information on the materials of interest for fireset apliat under conditions that approximate those expected in the environment.

Depending upon the fuel fire accident scenario, "yatus for the temperature, voltage and time will vary. For our investigations, conductivity changes for temperature increan 
to $600-700^{\circ} \mathrm{C}$ at a rate of $210^{\circ} \mathrm{C} / \mathrm{minute}$ were examined. Appiled voltages were up to $1000 \mathrm{~V}$ dc across flat plate specimens $0 \mathrm{~mm}$ in thickness (electric fields up to $u 4 \mathrm{x}^{3}$ volts $\mathrm{cm}$. The electrical experiments were conducted in a nitrogen environment since the atmosphere could be oxygen deficient during a fuel fire. In the materials examined, thermally-induced chemical and structural changes result in material decomposition at high temperature $[12,13]$. Consequently, tie clectrical data are taken when the material is in a state of non-equilibrim. Information on decomposition products and material mass los was obtained using mass spectroscopy (in vacuum and hemat gravimetric analysis in nitrogen and air). The themal aba are correlated with the conductivity resuls and provice insight into relationships between a lectrical conducton and Eharmal decomposition.

\section{MIAERILS}

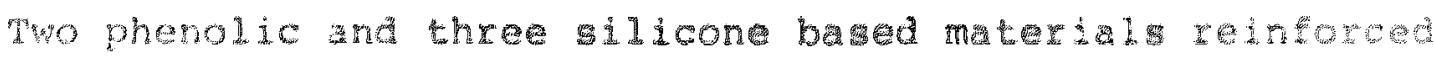

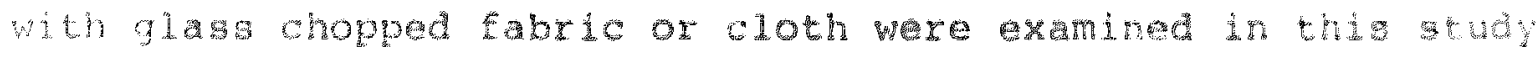
$[14,15]$. The phenolic and 11 icone rosing which are highiy orosinked were chosen for their high temperature gabiditis [15]. The samples examined herein used the same stating materials and molding or forming conditions as specified for Exreget housings.

\section{A. Phenolic Materials}

10.9135

The starting material, U. S. Polymeric FM-5135, contaris the Ironside chemical co. phenolic resin system 91 Low wh 
a chopped half-by-half inch glass fiber reinforcing filler [16]. The material is molded at Bendix Corporation, kansas city at a cure temperature of approximately $149^{\circ} \mathrm{C}$, pressure of 3185 psi for a period of 25 minutes. The material is a singie stage phenolic which utilized ammonia as a catalyst. Armonta is liberated during the curing process. This is of concern in utilizing this material for fireset applications because anmonia that may be Iiberated during lorg term storage may induce compatibility problems with other fireset somponents. $\underline{M X B-71}$

The starting material is Eiberite corp. MB-71, which is a blend of two resins. It is formulated using the Monsanto resin system SC-1008, a nylon modifier incorporated for toughness, and chopped hal $-b y-h a l f$ inch glass fabric resnercino. This material is also a one stage phenolic and utilizes a proprietry amine as a calyst. The materjal is molded at bendx, Kansas City, under the same conditiong as for the Fusiz material (i.e. $149^{\circ} \mathrm{C}, 3185 \mathrm{psi}, 25$ minutes). No ammonia mas been detected as a restit or the curing process $[17\rceil$.

\section{B. Silicone Materials}

$\underline{D C}-302$

Dow-Corning DC-302 is a eiberglass-filled nigh temperabura silicone resin. The starting material consists of choper glass fabric coated with a polyphenylmethysilosue restin in which is dispersed an iron-oxide/silicon-oxide filler 110 . The composition is approximately 328 resin, 46 fiber, and 22 particulate [19]. The material is molded at Bendix, 
Kansas City under approximately the same conditions as for the phenolics.

BRP-50201

This material is a Bendix, Kansas City formulaton of a glass mat impregnated with a silicon resin [20]. It is based or Dow Corning's $Q R-4-3136$ silicone resin and on a continuous strand fiberglass mat (M-8610) from Owens-Corning Fiberglas corporation. It consists of 53 glass, 32 resin and 15 risilers and additives. This material was developed by Bendix as a replacement for DC-302. since DC-302 is being discontinued by Dow Corning as a commeicial item. The molding process is the same as for the phenolics and DC-302.

$C 5-4202$

This material is a silicone-glass composite which usines a pre-pregnated continuous glass fiber cloth. The atering material is supplied by Ferro Corp. and is a composite of a silicone resin formulated by Ferro Corp. ICs-4202, baser on Dow corning DC-2106) wheh is impregneted on cantinuous woven fiber cloth (77812-glass from Corning). The materiel is supplied as a roll of pre-pregnated glass fabric. The cloth is cut to desired shape and parts are processed lat sand National Haboratories in Albuquerquel in an antoclave to 12 ply thickness. The material is vacuum sealed in a plaste bag and experiences a time, temperature, pressure cycle during processing. A two-stage processing operation in the autoclave is used. The first stage involves 150 psi pressure, $1777^{\circ}$ for one hour. The material is then postcured in the autoclate for 
3 hours at $177^{\circ} \mathrm{C}$. This is followed by a postoure under atmospheric pressure $2 \mathrm{c}^{\mathrm{C}} 204^{\circ} \mathrm{C}$ for 2 hours. The material is then further postcured at $249^{\circ} \mathrm{C}$ for times which are selected to vary from 4 to 24 hours. This material was deveioped in Revin Hirschbeuhler in the Composite Materials Developnent Division at Sandia National Laboratories [21].

\section{EXPERIMENTAL METHOD}

\section{A. Electrical Measurement Techniques}

Flat specimens, $40.3 \mathrm{~cm}$ thick in the shape of squares $33 \mathrm{~cm}$ on a side were used. Electrodes for two-terminal condutance (or resistance) measurements were circular (1.1.1 ch cimeter and were placed on opposite faces of the sample as shown in Fig. 1a. The guard-ring electrode confiquration of Fig. Ib louter guard ring grounded) was used to evaluate af:...: of surface currents. The rully electroded configuration P:. was used to determine effects of fringe fields associated wis the Fig. la arrangement.

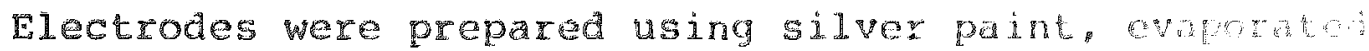
gold, or aquadag (graphite). There was no signifidar.t. dependence of the conductance on electrode materiai. Moment. the best adhesion was obtained with the silver eloctrodes. As a result, silver electrodes were used for most of the experiments reported herein. There is an indication that volatiles are partially trapped by the electrodas 1500 Appendix A). The configuration of Fig. la was found to the adequate for these experiments, in that there did not arpar to be any serious electrode problems related to rolatih labt m. 

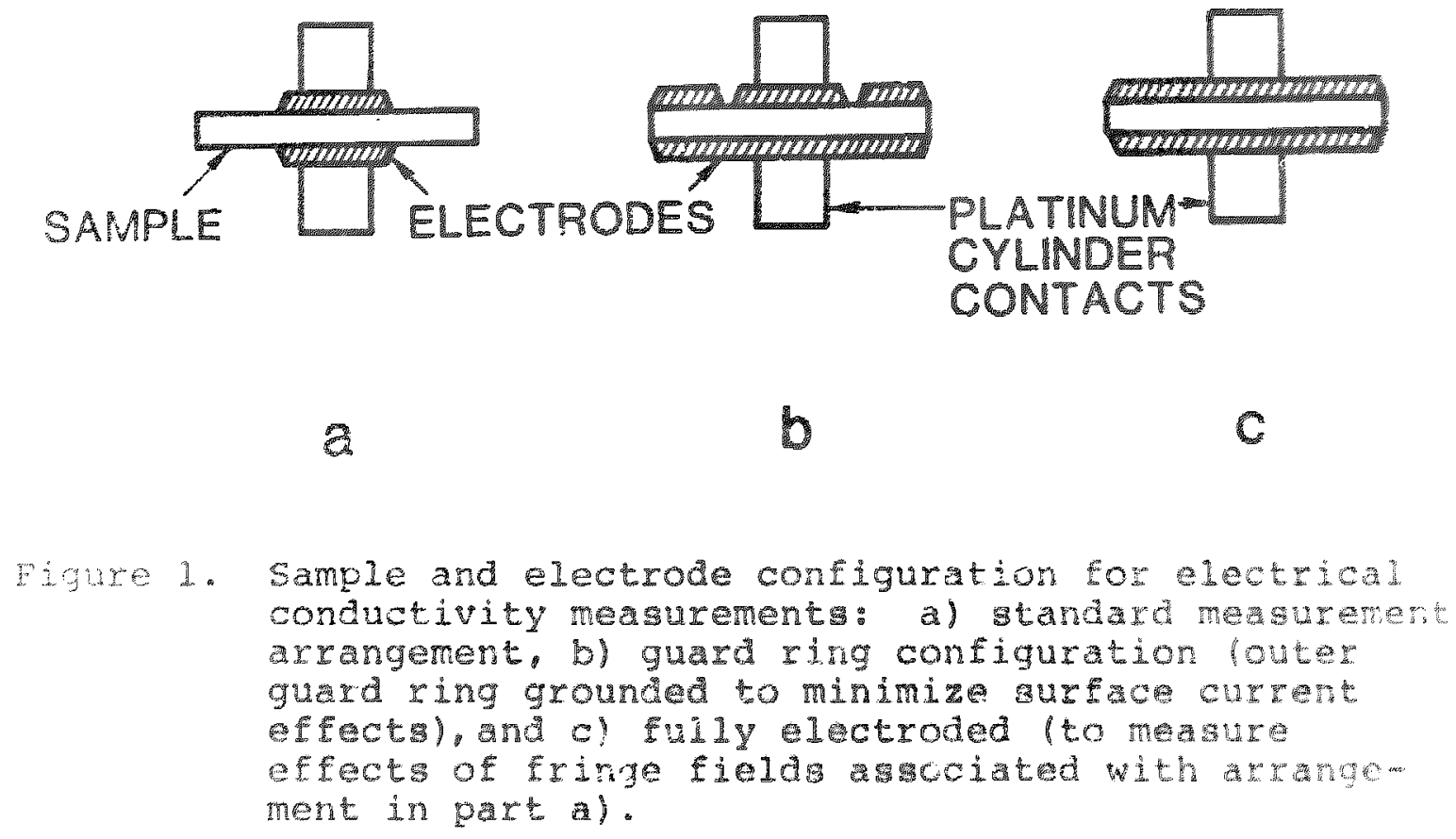

PLATHUN GONTACTS

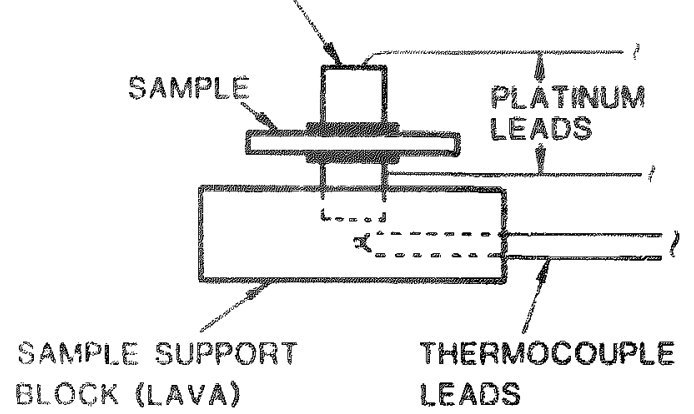

HOT ZONE

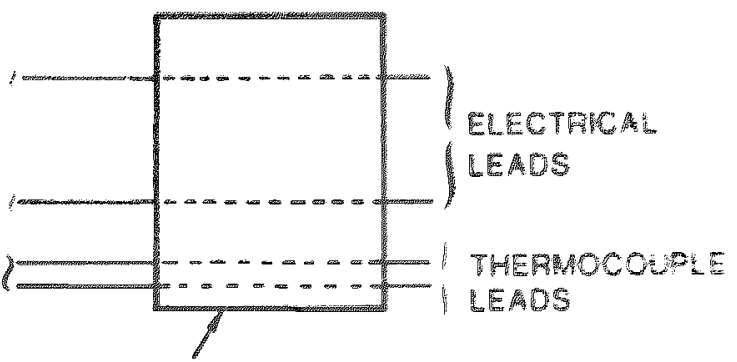

LEAD SUPPORT

BLOCK 'LAYAY

COLO ZONE

Figure 2. Sample holder configuration. 
Electrical contact was made to the electroded samples using platinum cylinders as chown in Fig. 2. The bottom cylinder served to support the sample above the insulating support block. Platinum wires were used as electrical leats. These wires were encased in separate alumina tubes passing from the high temperature zone of the furnace to the low temperature region where they were supported by another insulating block (1ava or boror nitride). This configuration minimized leakage currents since current paths between the electrodes were not in the hot zone of the furnace. Leakage currents mere below $10^{-9}$ amps at $1000 \mathrm{~V}$ for temperatures below $400^{\circ} \mathrm{C}$. At higher temperatures the leakage currents increased somewhat but were below $10^{-7}$ amps (at $\left.1000 \mathrm{~V}\right)$ at $700^{\circ} \mathrm{C}$. This is three to wour orders of magnitude less than conduction obtained from the samples at these temperatures.

The temperature was measured using a thermocouple moth tas in the sample support block as indicated in Fig. 2. The temperature lag between the sample support block (where the recording thermocouple was located and the sample wat measured (at the $10^{\circ} \mathrm{C} /$ minute heating rate) and bas found to be within $10^{\circ} \mathrm{C}$ over the temperature range examined.

For the conductivity experiments, the samplo nolder assembly (Fig. 2) was positioned in an open-onded guartz tube which facilitated loading and positioning in the furrace assembly. The furance assembly was made by Marshall Furnace co. and contained a tubular chamber which could be sealed to control the atmosphere. Separate thermocouples were used for 
the furnace control and the sampla temperature. In these experiments the furnace assembly was flushed with nitrogen and ther sealed at a gauge pressure of 010 psi. The possibility of leakage currents through the vapors emitted from the samples during decomposition was also explored and was found to be insignificant. After a series of tests were completed, some of the chemicals in the heated gas condensed after cooling on parts of the sample holder. After a number of tests this caused some conduction but generally in the $10^{-8}$ A range or less. By baking out the sample holders and the quarta tube at $600-700^{\circ} \mathrm{C}$ after tests, this leakage was reduced to below $10^{-9} \mathrm{~A}$. The electrical measurement system schematic is shown in Pig. 3. $\Lambda 100 \mathrm{~K}$ ohm resistor was placed in series with the high potential lead to limit short circuit currents. Ass automatic data acquisition system wes used. The system was programable so that several voltages could be sequantially applied to the specimen at selected time intervals. voluon levels of $100,300,500$ and 1000 were used and were applad for 2-6 seconds at each voltage setting as the temperature was increasing at a rate of $10^{\circ} \mathrm{C}$ per minute. Temperature and current readings were taken at each voltage setting.

Possible effects associated with the time duration of the applied voltage were examined. An experiment was conducted in which the voltage was applied continuously at $1000 \mathrm{v}$. The results were compared with those from a sister sample cut from the same disk which was tested in the same system following the normal time interval step sequence. The results showed that 


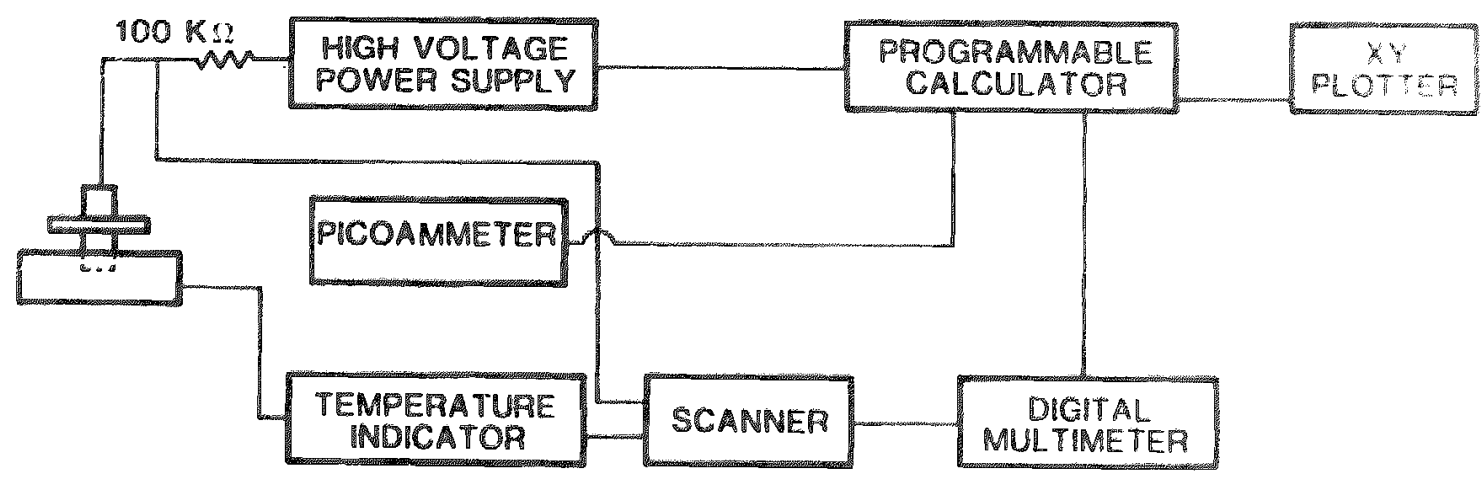

Figure 3. Electrical measurement system schometio whom: the major components: Programmable caloulate (Monroe Model 1880), xi plotter (Hewiett patis Model 9872A). Operational Power Suppl: (kepeo Model ops 2000B), Digital Picoameter (Reithle: Model 445). Digital Multimeter (keithley vodal 172A), Scanner (Reithley Model 702), Digital Temperature Indicator (Omega Model 199 ). 
the length of time for voltage application did not significantly effect the measurements. This has relevance to the determination ot possible polarization effects which is discussed in later sections.

The electrical conductivity (reciprocal of resistivity) was determined from

$$
\sigma=k \frac{l}{A} \frac{I}{V}
$$

where is the sample thickness, A is the electrode amea, I is the sample current, $\checkmark$ is the applied voltage, and $k$ is a geomeri.. correction for fringing fields. For the geometry of Fid id * Was determined experimentally to have a value of 0.72 lnote that $k=1$ for the geometry of Fig. lo).

The accuracy of the conductivity tamperature dependance data, estinated from run-to-run reproducibility for given material (sister samples), was found to be within a sator of two of the measured conductivisy value.

\section{B. Thermal Anaysis Techniques}

Thermal property measurements were made using high temperature mass spectroscopy and thermal gravimetrio analysis. The mass spectrometer was a Bendix Model 3015 Time-of plint Mas Spectrometer which was equipped with a high temperature nudsen inlet system. The spectra were obtained in vacuum A Bued temperatures with an electron beam energy of $65 \mathrm{ev}$. Tine at temperature was 230 minutes. A heating rate of $100 \mathrm{c}$ minute was employed between temperature settings. Data were taken to $2400^{\circ} \mathrm{C}$. No changes in the spectra were observed 
between 4350 to $400^{\circ} \mathrm{C}$ except for a continuous increase in total pressure and ion current.

Two thermogravimetric analyses techniques were used. In one method the samples were heated in both air and ficring nitrogen for one hour at $100^{\circ} \mathrm{C}$ intervals up to $700^{\circ} \mathrm{C}$. The heating and cooling rates were $25^{\circ} \mathrm{C} /$ minute. Percent weight loss was determined following each temperature cycle. The second method involved measuring weight loss while heating samples at $10^{\circ} \mathrm{C} / \mathrm{minute}$ in nitrogen. A DuPont Model 990 Thermal Analyzer with a Model 951 Thermogravimetric Analyzer were usea for these measurements. The precision associated with these techniques was estimated to be \pm 0.1 and \pm 0.5 wt.

IV. ELECTRICAL RESULTS

A. Phenolic Materials

Typical current versus temperature data obtained at four different applied voltages on as-nolded phenolic pM-5135 and MXB-71 samples are shown in Figs. 4 and 5 , respectively. Mr. results show two peaks in the corauctance at 250 and $400 \%$ The peak at $2400^{\circ} \mathrm{C}$ is more pronounded in $M \times B-71$ than in the FM-5135 material. Analysis of the current-voltage data shows ohmic (or nearly ohmic) conduction characteristics, in that the sample current scales nearly linearly with applied yoluas. Deviations from ohmic behavior occur principally in the temperature regions below $270^{\circ} \mathrm{C}$ for FM-5135 and below $3090 \mathrm{C}$ for MXB-71. Non-ohmic behavior is most pronounced in the low temperature insulating state $\left(<100^{\circ} \mathrm{C}\right)$ and ir the region of the conductivity peak at $200-300^{\circ} \mathrm{C}$. In these regions corduct: 


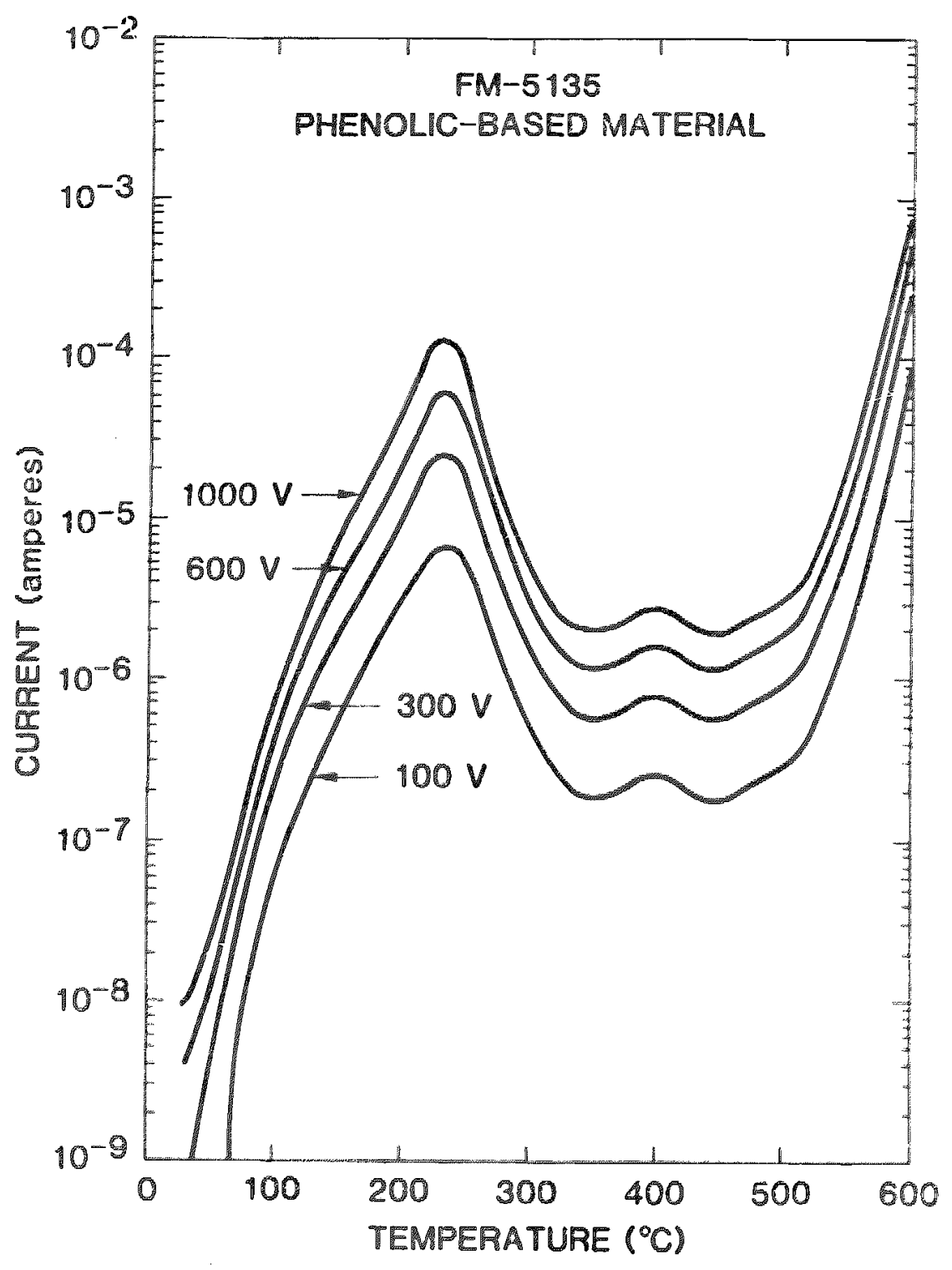

Figure 4. Typical sample current versus temperature for sm-5135 phenolic as a functior of voltage. This material had aged (in the ambient enviroment) for $2-3$ years prior to these experiments. Results show" conductivity peaks at 4250 and $400 \circ \mathrm{C}$. Analysis of current-voltage data indicate deviations from ohmic conduction behavior in the region $5270^{\circ} \mathrm{C}$. 


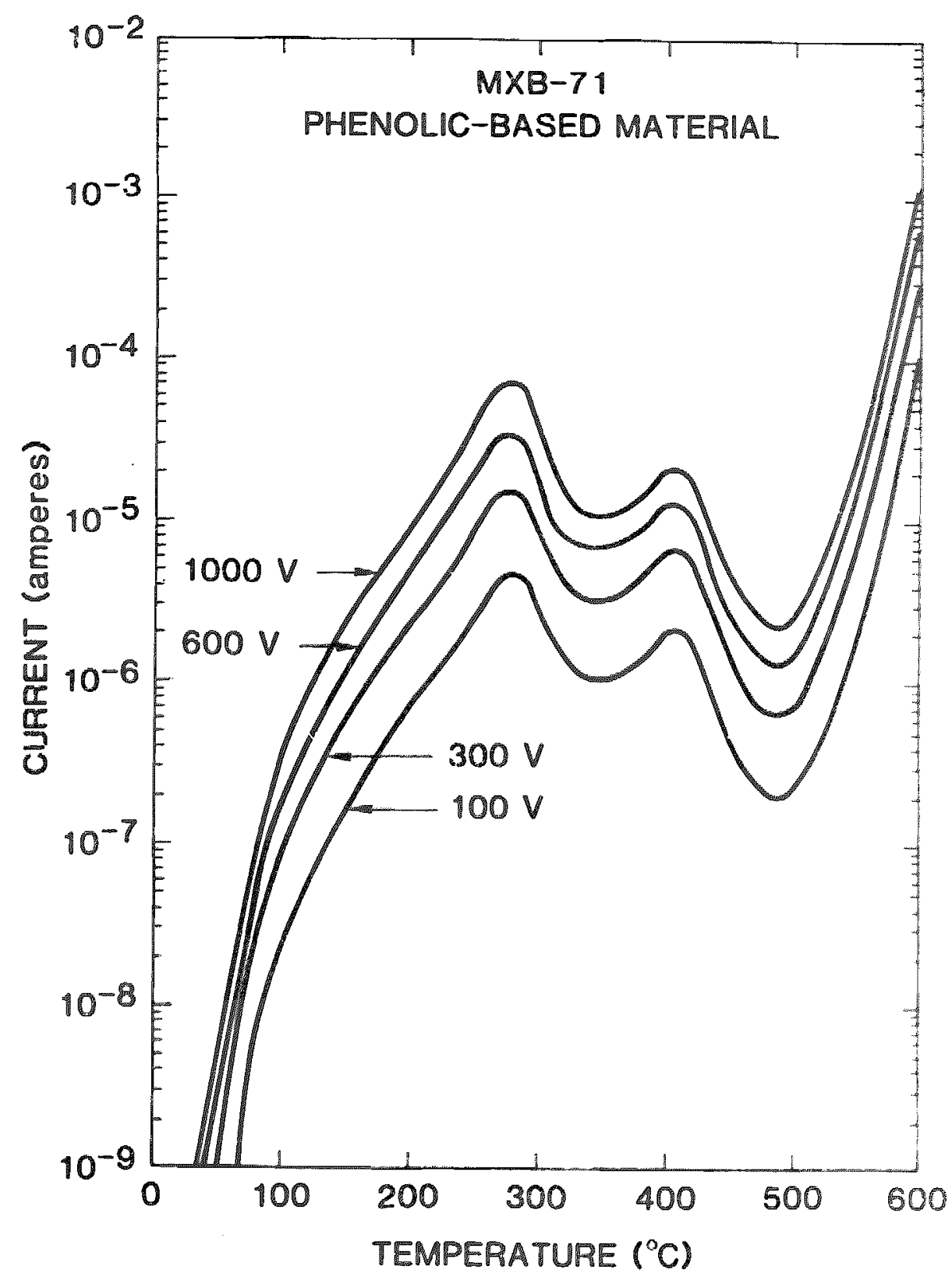

Figure 5. Sample current versus temperature for $M A B-71$ phenolic as a function of voltage. This materiat had aged in the ambient environment for $2-3$ years prior to these experiments. Pesults show conductivity peaks at 270 and r $400^{\circ} \mathrm{C}$. Fisuly of current-voltage data indicate deviations rom ohmic conduction behavior in the region $300 \%$. 
values determined from the 100 and $1000 \mathrm{~V}$ data differed by a factor of at most 2. In plots of the concuctivity data throughout this report, temperature regions where there are significant deviations from ohmic behavior are indicated by the dashed Iines.

The conductivity temperature dependence was measured on a number of samples from various lots of material. Resubts showed good repeatability in conductivity chasacteristics from sample-to-sample within a given lot of material. Lotto-lot variations are shown in Figs. 6 and 7 and are more pronounced in the FM-5135 phenolic than in MKB-71. The extert to which these differences are associated with starting materials (formulation or age), processing conditions or simple age is not known.

The effects of postcuring in air on the electrical con ductivity are ghown in Figs. 8-10. The data in Figs. and aro Eor Fr-5135 material from lots with different asmoldea conductivity characteristics. The data in Fig. 10 are tor M:B-71 material. Results show that in all of these materials postcures of $143^{\circ} \mathrm{C}$ for 16 hours followed by $200^{\circ} \mathrm{C}$ for one hour reduce the conductivity in the low temperature region $\left(5250^{\circ} \mathrm{C}\right.$, reduce somerhat the magnitude of the conductivity peak at $250^{\circ} \mathrm{C}^{\circ}$ and shift the peak to a higher temperature. Postcures to $250^{\circ}$ for one hour further reduce the conductivity in low tempersture regions and eliminates (or significantly reduces) the conductivity peak at $250^{\circ} \mathrm{C}$. Note that ohmic conduction was observed throughout a greater temperature range for the material 


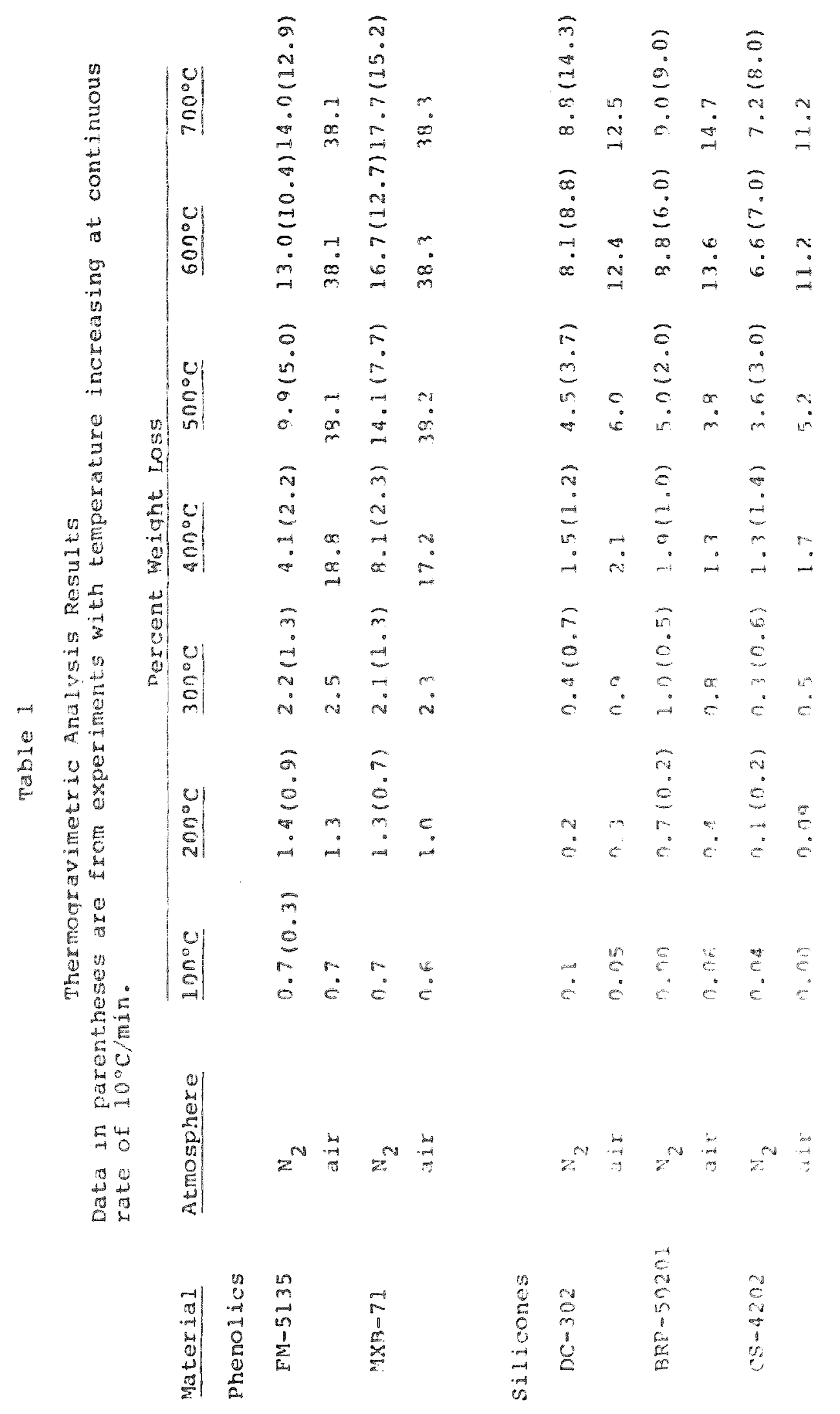




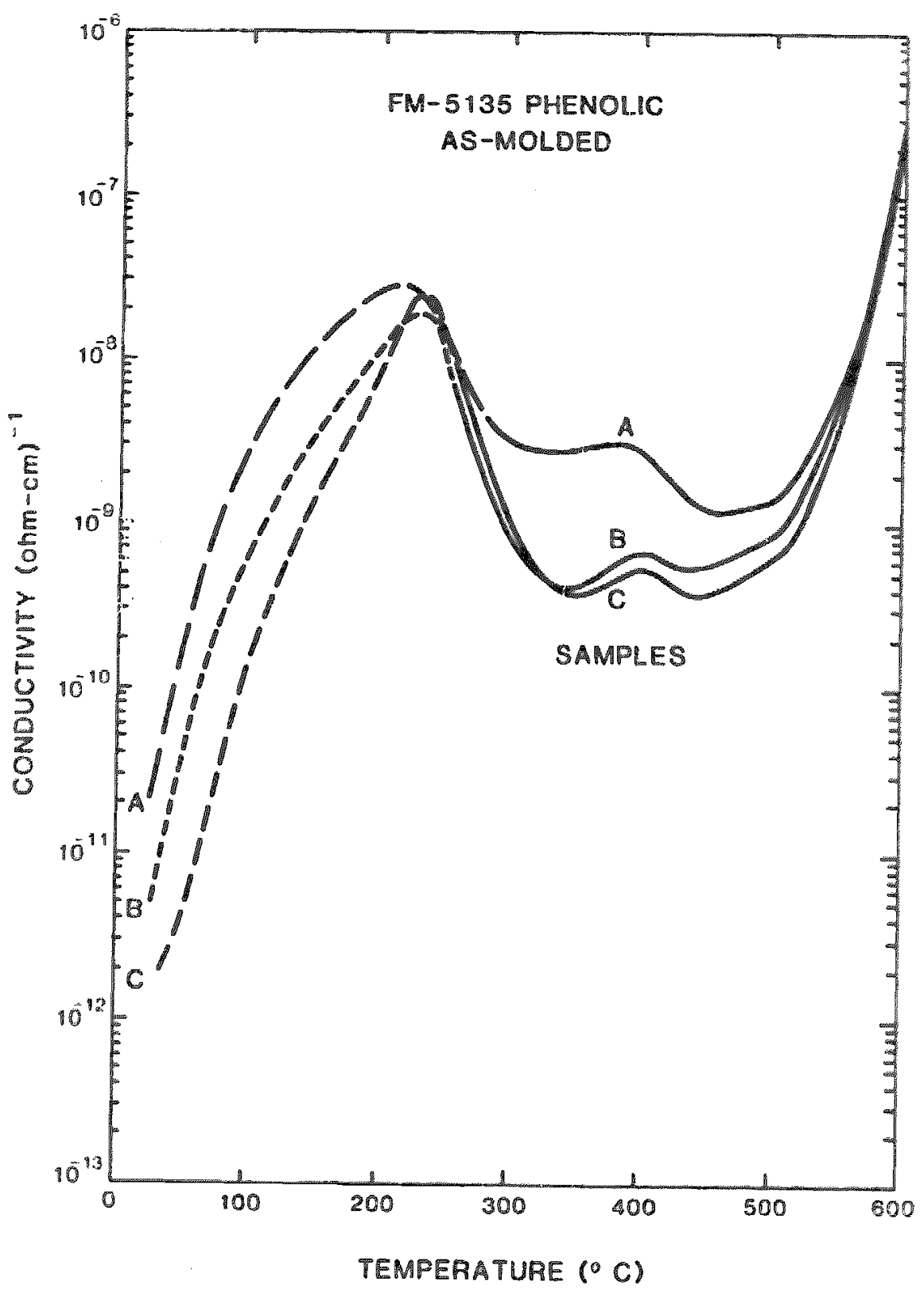

Figure 6. Conductivity temperature dependence for Fry-5135 phenolic showing lot-to-lot variations. Sample $A$ : starting material w months old, time since molding 21 month. Sample B: starting material 02 years old, time since molding w month. Sample C: starting material age unknown, time since molding $2-3$ years. Conductivity differences may be due to starting material (formulation or age), processing conditions or sample age. Dashect portion of curves indicates regions of non-ohme behavior. 


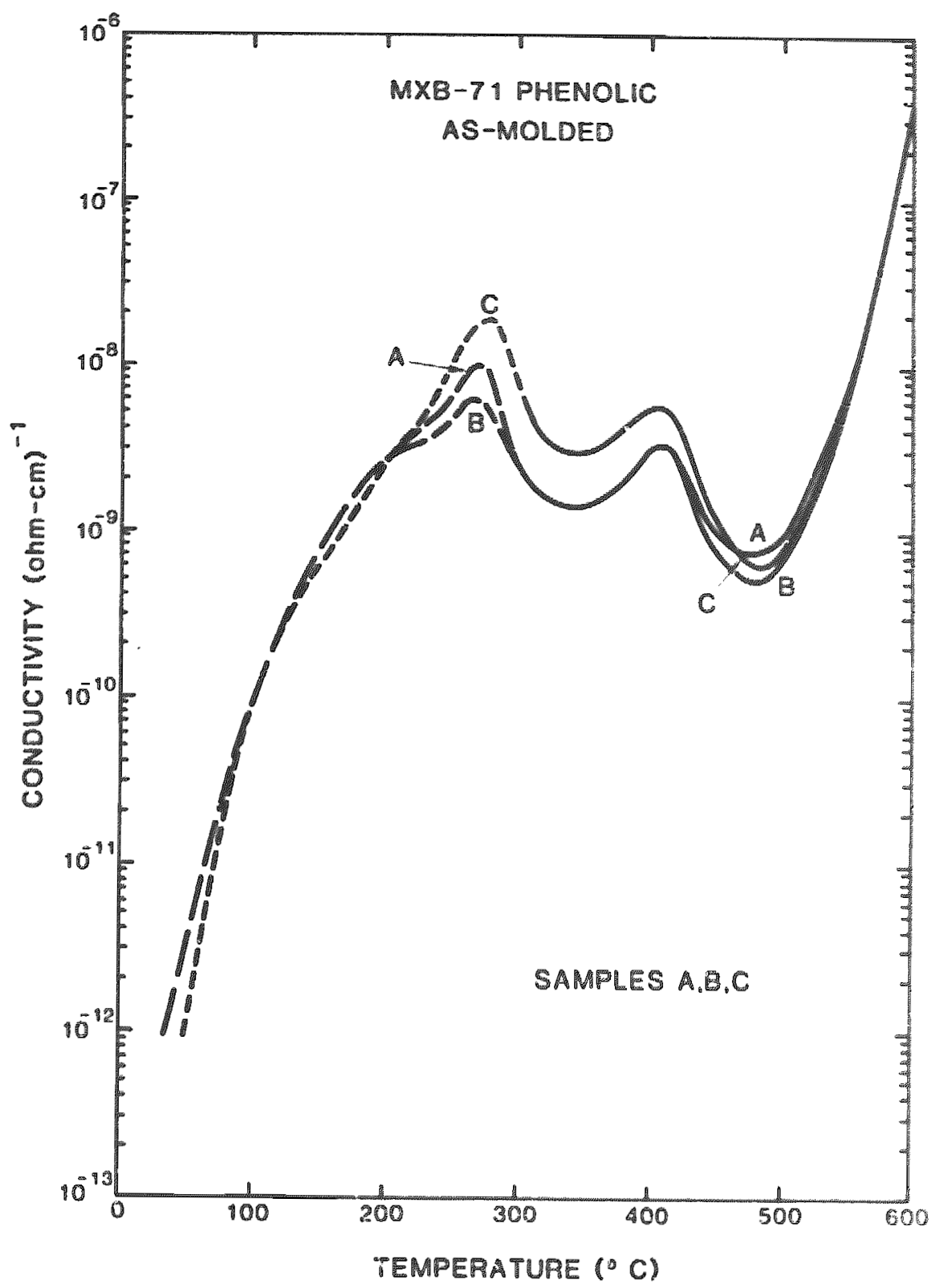

Figure 7. Conductivity temperature dependence for MB-71 phenolic showing lot-to-lot variations. Sample $A$ : starting material $\sim 5$ months old, time since molding 21 month. Sample B: starting materta? n.3 years old, time since molding n month. Sample C: starting material age unknown, time since molding 2-3 years. Conductivity differences may be due to starting material (formulation or age), processing conditions, or sample age. Dashed portion of curves indicates regions of non-onmin behavior. 


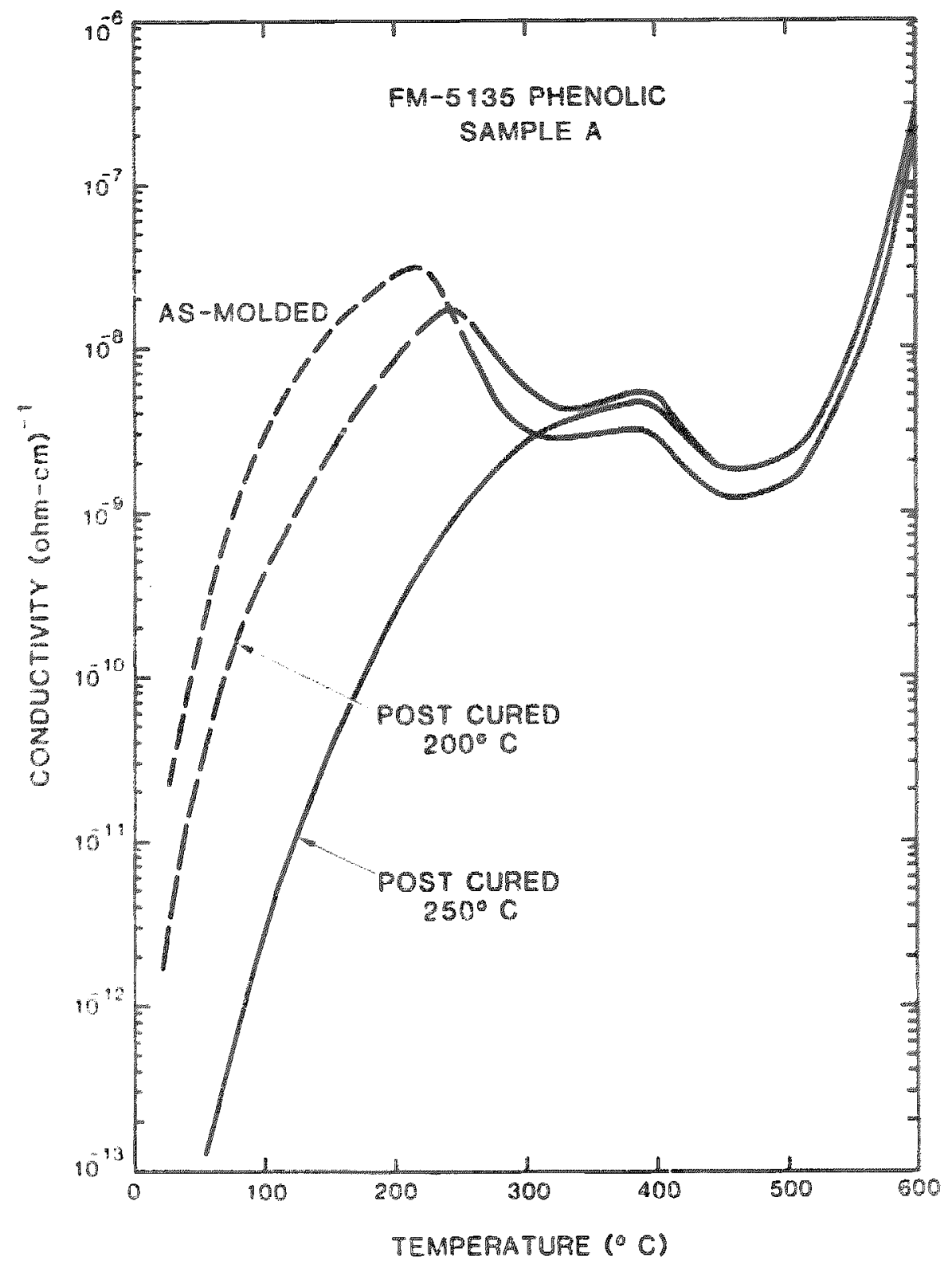

Fique 8. Conductivity dependence on postcuring (in arr) for FM-5135 phenolic. Data are for samples prepared with starting material us months of age and measured $I$ month after molding (sane material as Sample $A$ in Fig. 6). Dostcure conditions are given in test. Dashed portion of curves denotes non-ohmic regions. 


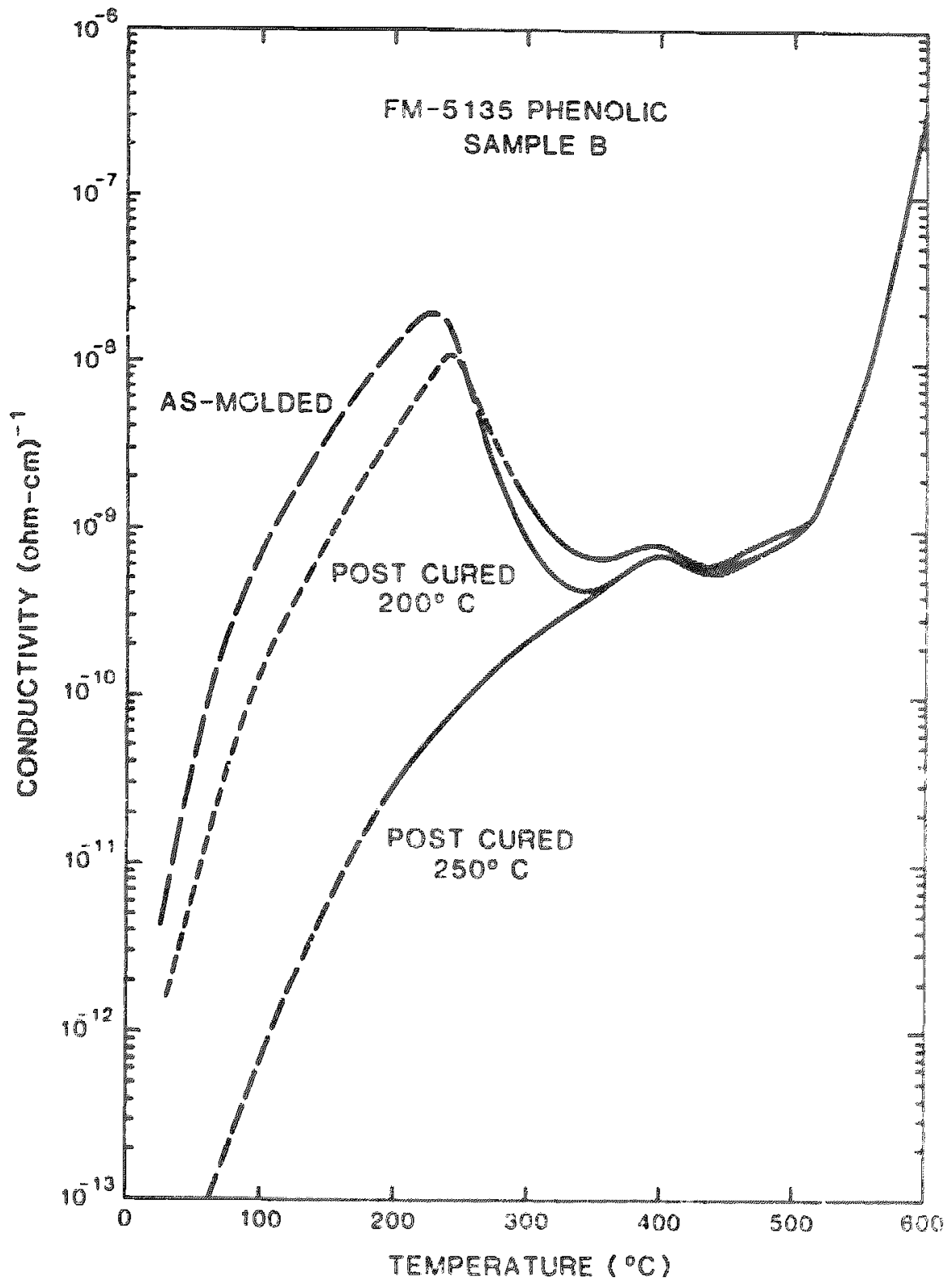

Figure 9. Conductivity dependence or postourng (in air) for FM-5135 phenolic. Data ree for sambles prepared with starting material over 2 yome old and measured 1 month after moling lsand material as sample $B$ ir Fig. 6). Postone conditions are giver in text. Dashed portin of curves denotes non-ohmic region. 


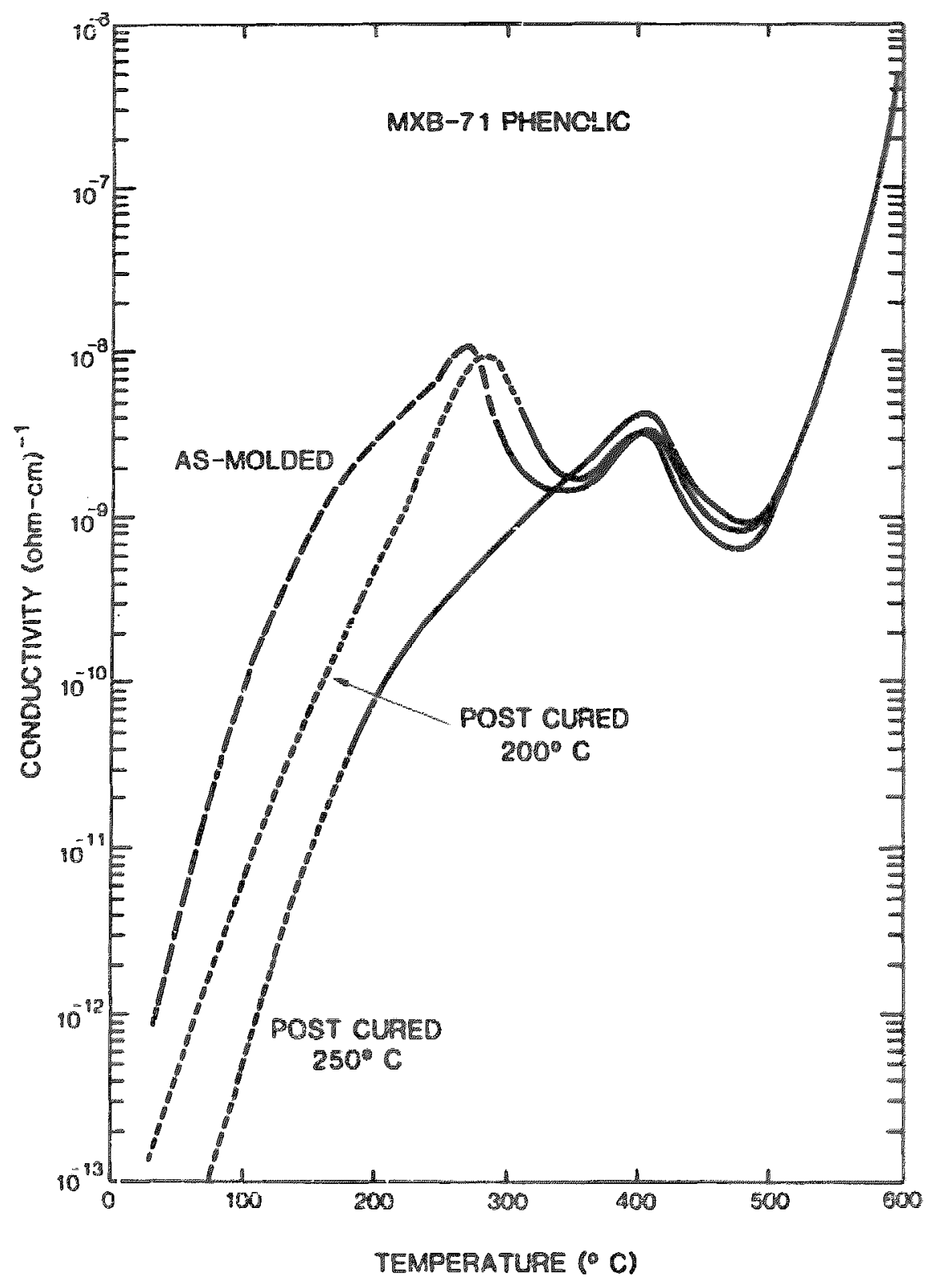

Wigure 10. Conductivity dependence on postcuring (in air) for MXE-71 phenolic. Data are typical for these materials i.e., variations from lot-to-lot were not as pronounced as for PM-5135, see Figs. and 9). Postcure conditions are given in text. Dashed portion of curves denotes non-ohmic region. 
postcared to $250^{\circ} \mathrm{C}$ (i.e. after elimination of the conductivity peak at $\sim 250^{\circ} \mathrm{C}$ ).

Visible changes in the coloration of the materials were observed as a result of postcuring and cycling to high temperature. Postcures to $200^{\circ} \mathrm{C}$. for one hour did not change the appearance of the phenolics in comparison with the as-molded material. Postcures to $250^{\circ} \mathrm{C}$ for one hour caured a notable darkening of the material. For rapid heating and cooling rates some delamination occurred. Consequently, for postcuring to $250^{\circ} \mathrm{C}$ heating ratr. were used which were comparable to those utilized in the cicotud experiments where no delamination occurred.

Upon temperature cycling to $600^{\circ} \mathrm{C}$, the material fumbry pyrolyzed, became porous, and developed a blackish appearance. The electrical contacts, made using silver paint, did reman intact arter cycling to $600^{\circ} \mathrm{C}$. There were small regions with the electrode which appeared porous. This could have result from the decomposition process.

The temperature dependence of the conductivity of a pyrolyzed FM-5135 sample was measured after it was cycled to $2610^{\circ} \mathrm{C}$ in nitrogen. The results are shown in Fig. 11. The data are compared with those obtained on the sample in the as-molded state. Results show that conductivity peaks are completely eliminated after cycling to $4610^{\circ} \mathrm{C}$, but the resulting material is fairly conductive. Upon heating to higher temperatures, the material continued to pyrolyze (carbonized) and the conductivity increased further. The most pronounced changes (increases) were in the lower 


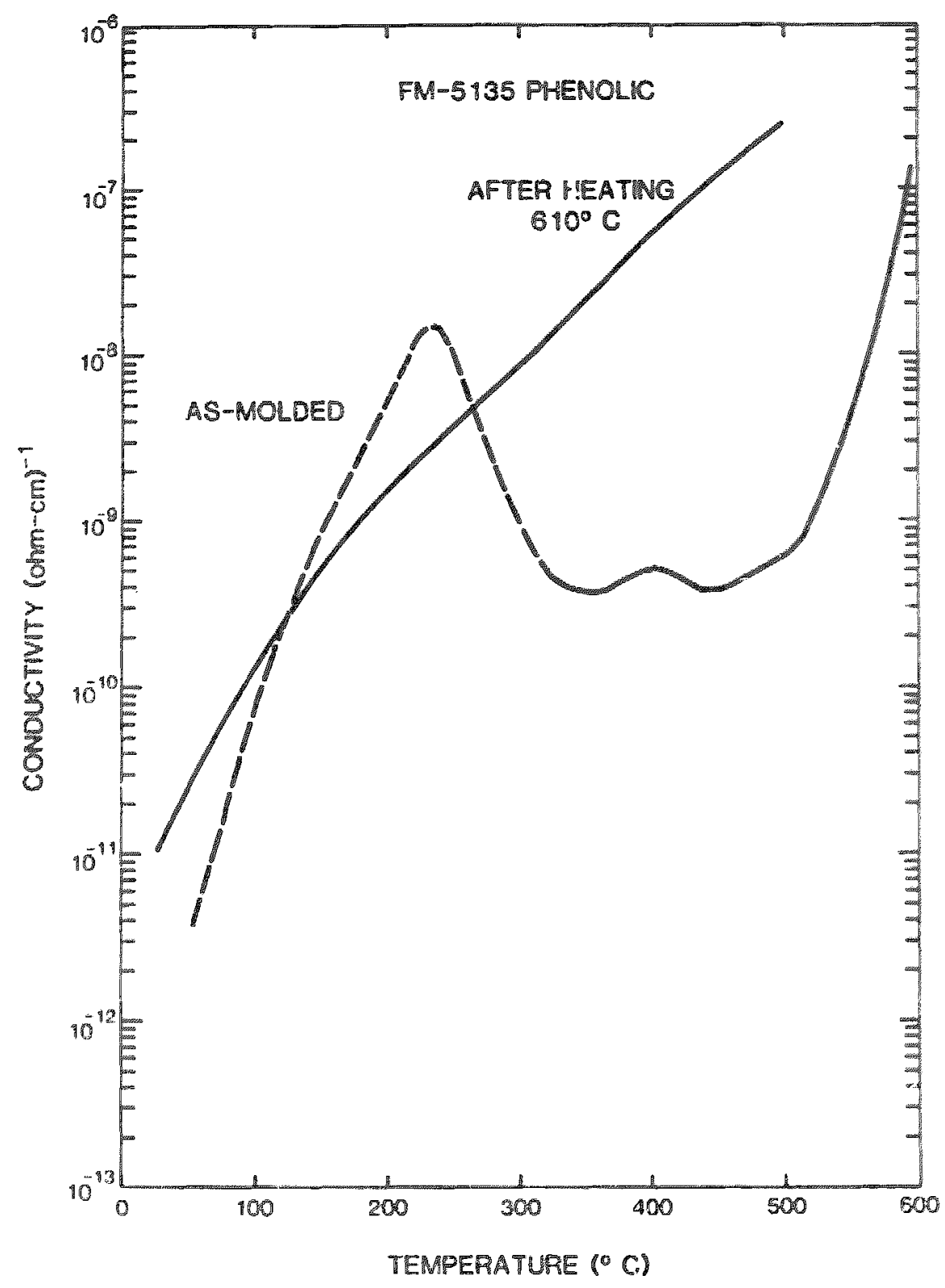

Figure 11. Conductivity temperature dependence of $F M-5135$ phenolic: as molded and after temperature cycling to $610^{\circ} \mathrm{C}$. Dashed portior of curve denotes non-ohmic region. 
temperature region. The carbonized material exhibited onmic conductance characteristics.

Surface conduction did not appear to be significant for pronounced in these materials. Measurements made using the three-terminal guard ring technique of Fig. Ib louter guard ring grounded) on pyrolyzed material (after heating to $0600^{\circ} \mathrm{C}$ ) showed that the measured conductivity was within 10 s of that measured using the standard technique (no guard ring Fig. 1a). Further evidence that surface conduction was not significant was seen in the results of four-terminal experiments discussed in Appendix $\mathbf{A}$.

Polarization effects were also examined. As mentoned in Section III, the length of time for application of voltage did not significanty effect results auring heating cycle. Furthermore, the voltage polarity was also reversed severa times during some of the conductivity runs, producing only minor changes on the conductance (within wov). In adition to these regults, polariation expeximents were conducted at a fired temperature of $160^{\circ} \mathrm{C}$. The time dependence of the sample current was measured after application of voltage $(1000 \mathrm{~V})$. The voltage polarity was also reversed ciuring these experiments. The initial experiments were on materials which had not been postcured. The results were difficult to interpret since time dependent effects related to curing as well as possible polarization phenomena were observed. Experiments at $160^{\circ} \mathrm{C}$ on materials which had been postcured to $200^{\circ} \mathrm{C}$ indicated that some polarization phenomena mat ocour. 
but again the affect on conductance was not greater than $10 \%$. Similar polarization experiments were not conducted at higher temperatures because of complicating effects associatec with material decomposition. No significant polarization was observed in the carbonized material. These results suggast that conduction is principally electronic in character in the carbonized material and in the postcured material below 22000 .

\section{B. Silicone Materials}

The temperature dependence of the sample current as a function of applied voltage for the silicone materials is shown in Figs. 12-14. Analyses of these data show nearly ohmic conduction, Hith deviations from ohmic behavior being not as pronounced as for the phenolics. Some non-ohmic behavior occurs throughout much of the temperature range for these naterials in the as-prepared state and after cycling to high temperature. Generally conductivity increases of wos were observed over the poltage range of 100 to $1000 \mathrm{~V}$. More signficant deviations rom non ohmic behavior (similat to those for the phenolics) occurred in the low temperature insulating state and at high temperatures $2450^{\circ} \mathrm{C}$. These regions are donoted by the dashed portions of the conductivity curves which are given in Figs. 15-17. The conductivity temperature dependence is considerably different for these materials than for the phenolics. Specifically, the conductivity is much reduced in the lower temperature region and the conductivity peaks are less pronounced. 


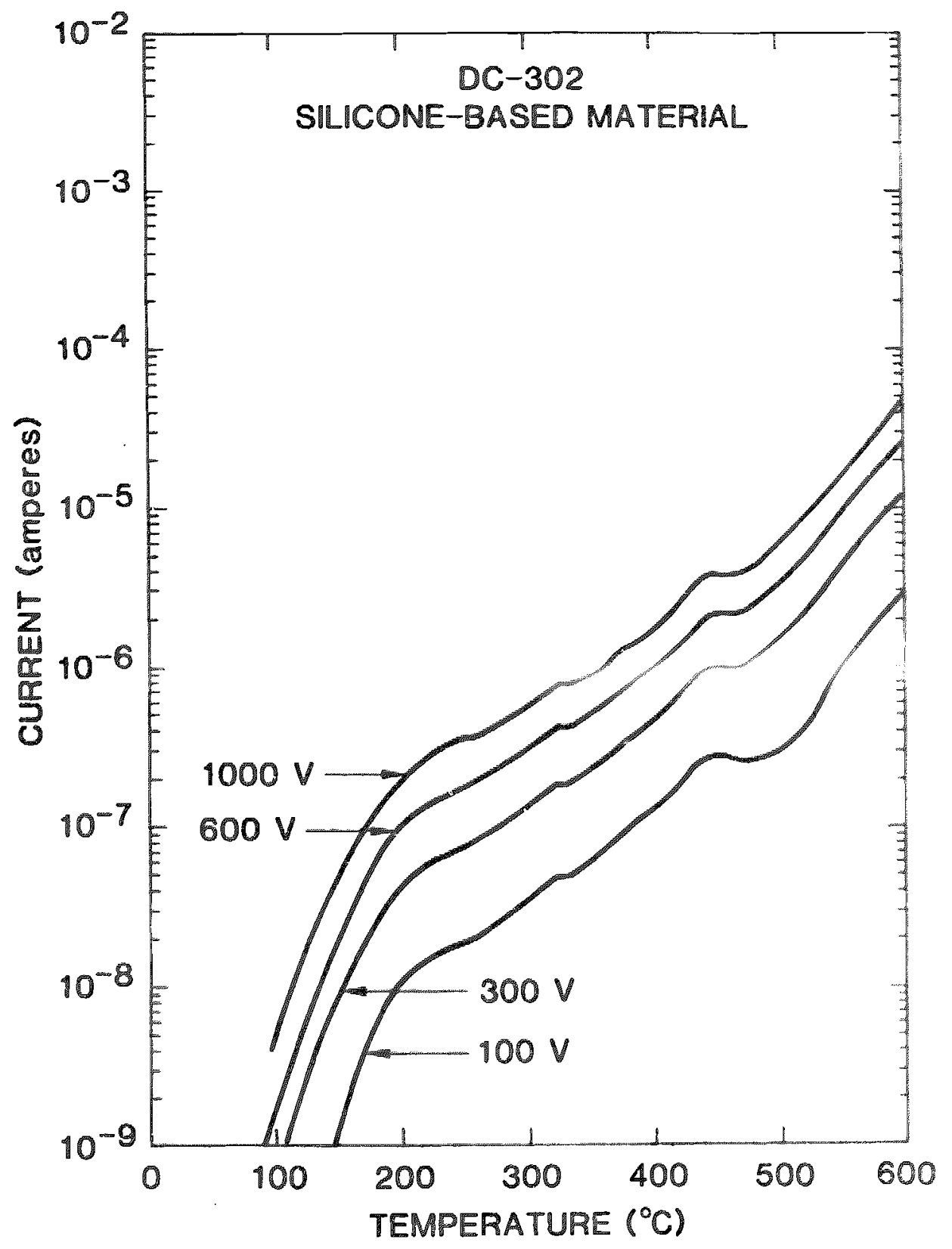

Figure 12. Sample current temperature dependence as a function of applied voltage for a typical DC-302 silicone sample. 


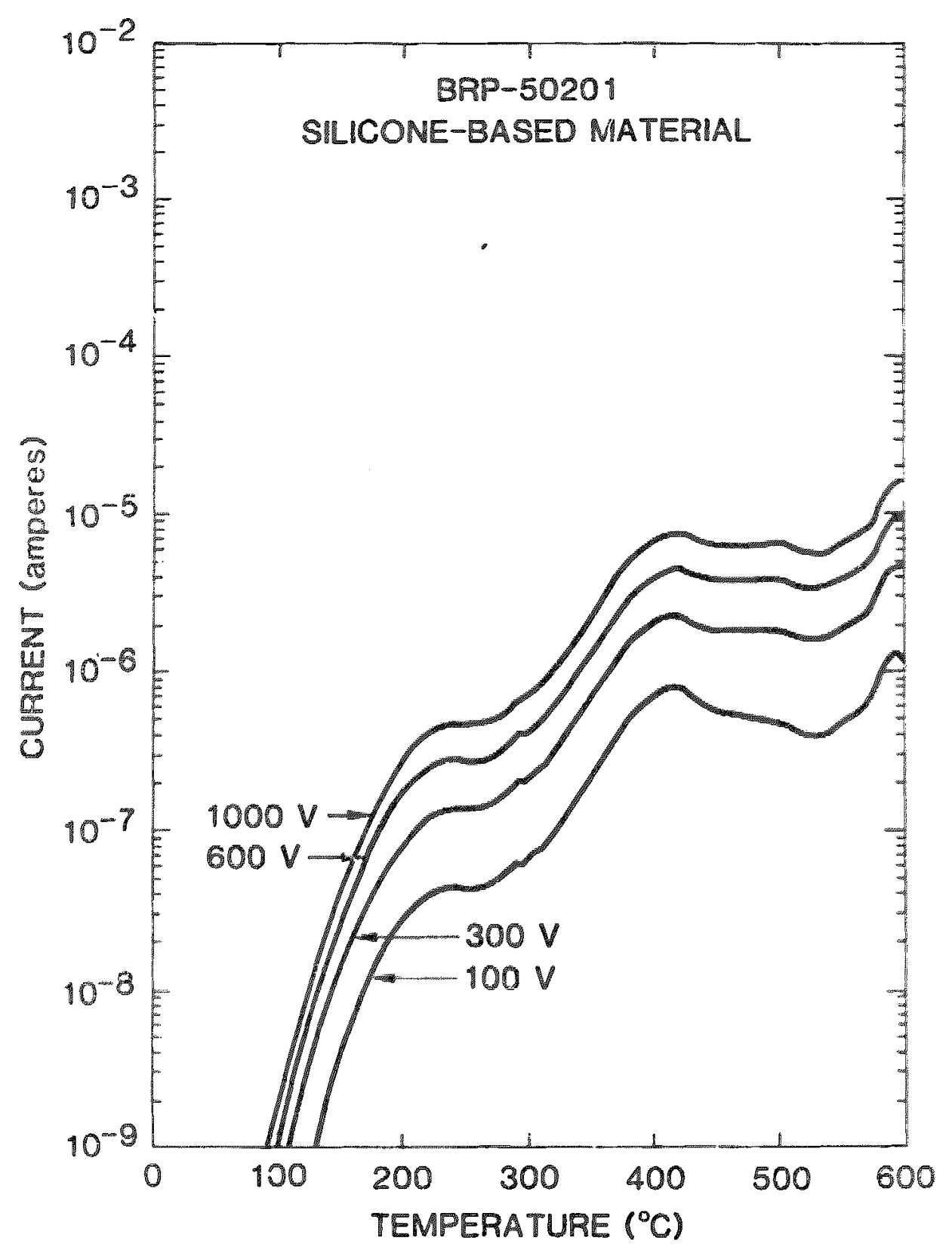

Figure 13. Sample curcent temperature dependence as a function of applied voltage for a typical BRP-50201 silicone sample. 


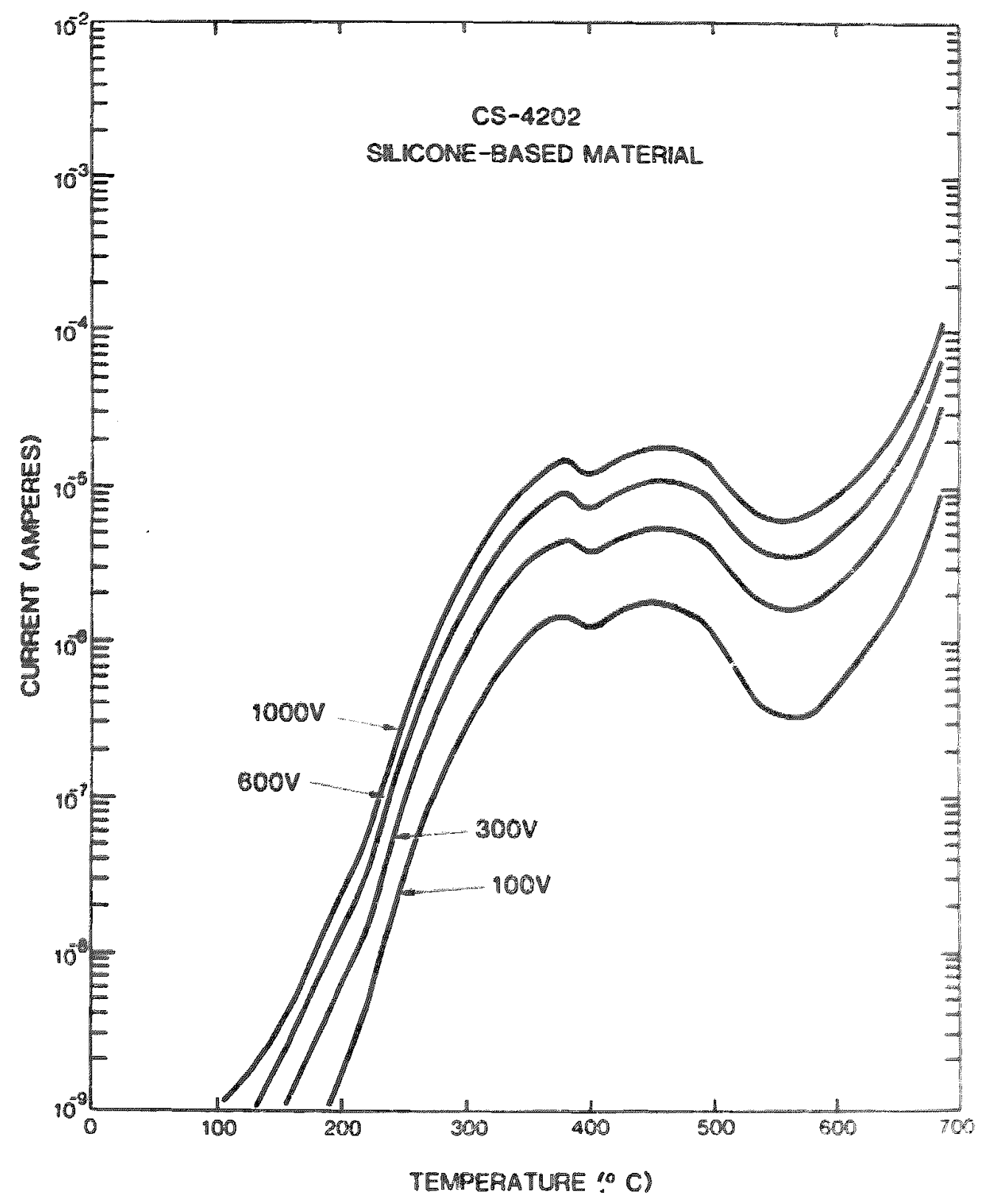

Figure 14. Sample current temperature dependence as function of applied voltage for a typical silicone-glass composite, CS-4202, sampla. 


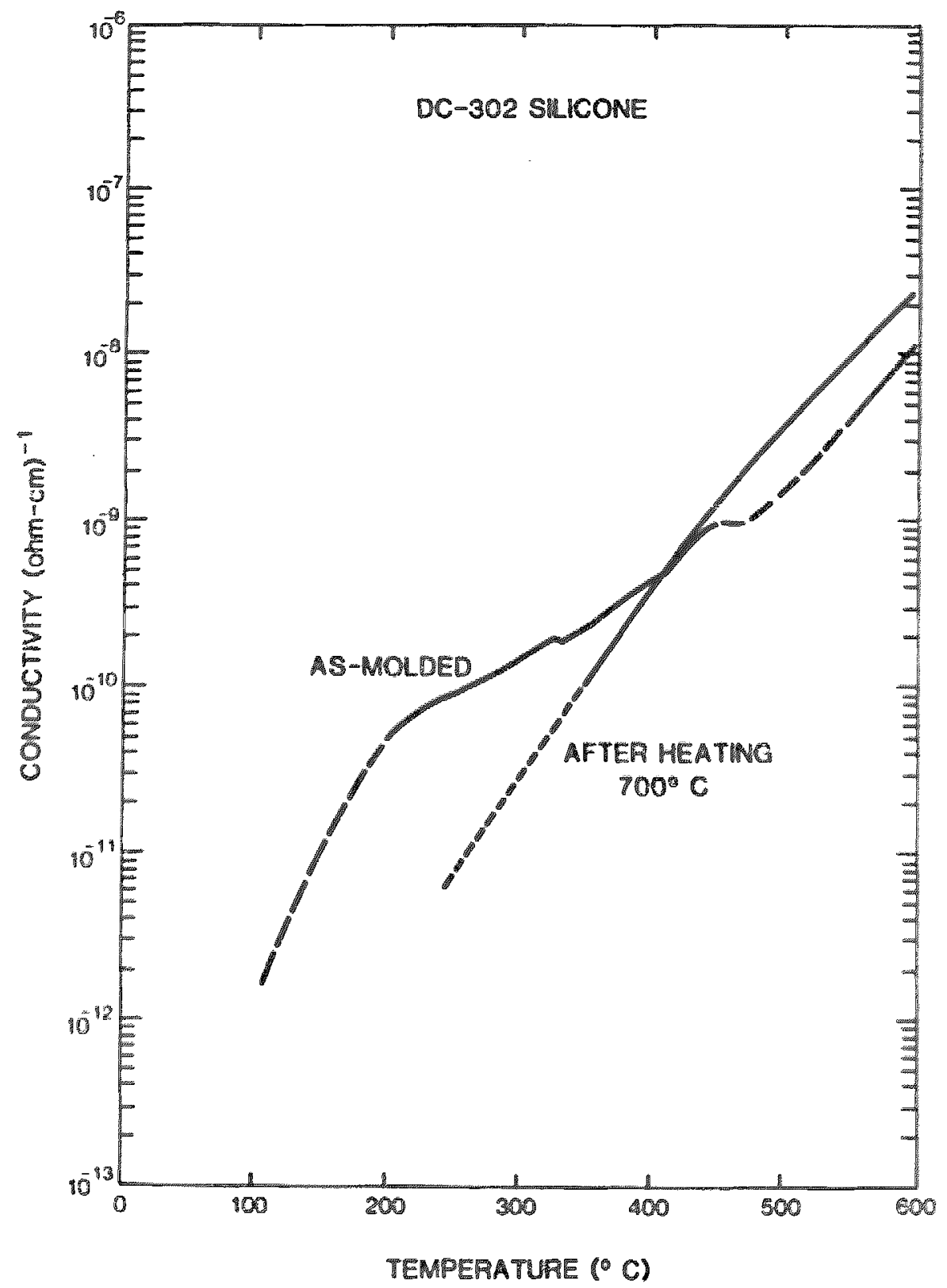

Figure 15. Conductivity temperature depencence for DC-302 silicone material: as-molded and after temperature cycling to $700^{\circ} \mathrm{C}$. Dashed portion of curves denotes non-ohmic regions. 


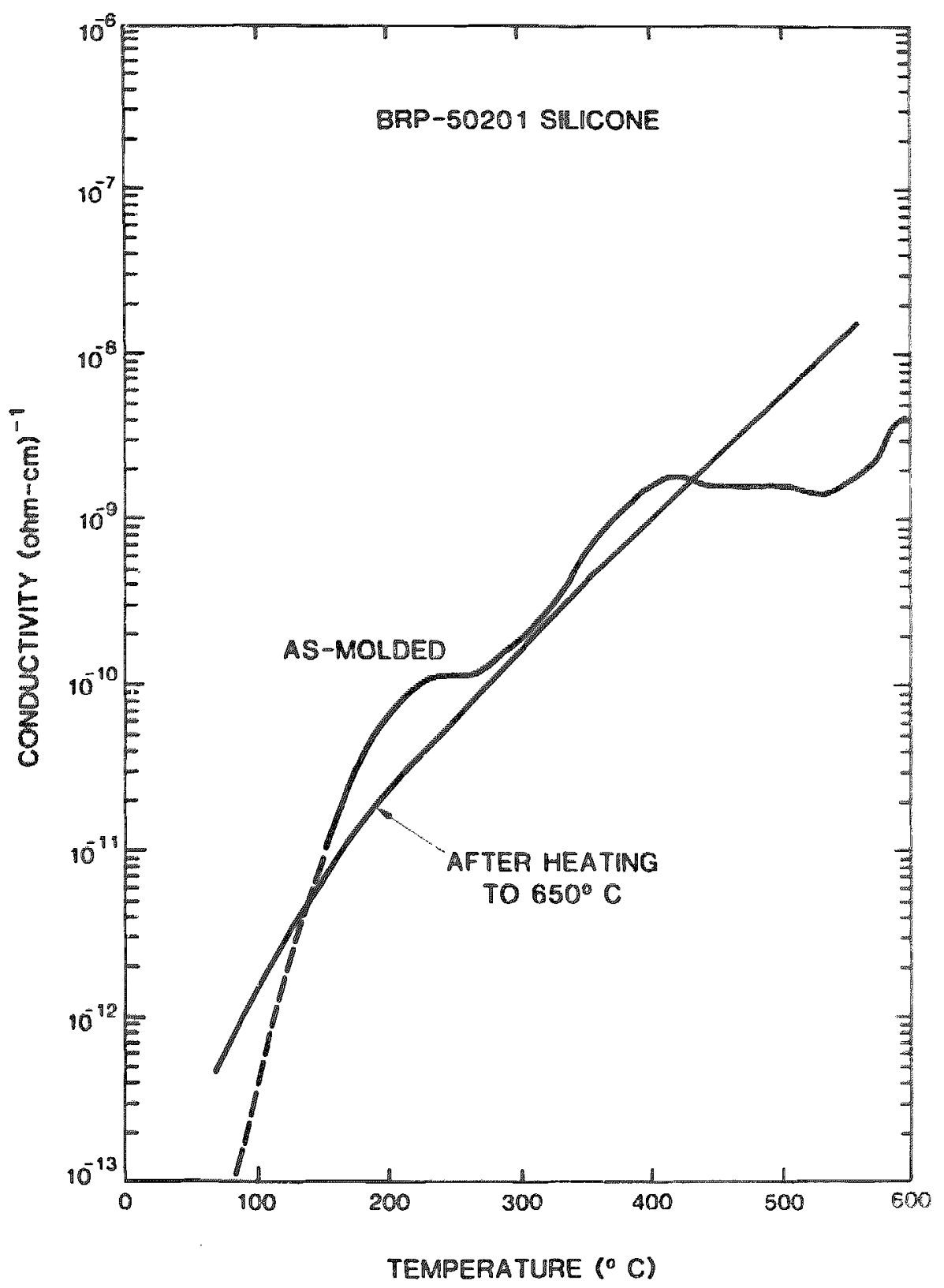

Figure 16. Conductivity temperature dependence of $B P P-5020$ : silicone material: as-molded and after temperat. cycling to $650^{\circ} \mathrm{C}$. Dashed portion of curves chartes: non-ohmic regions. 


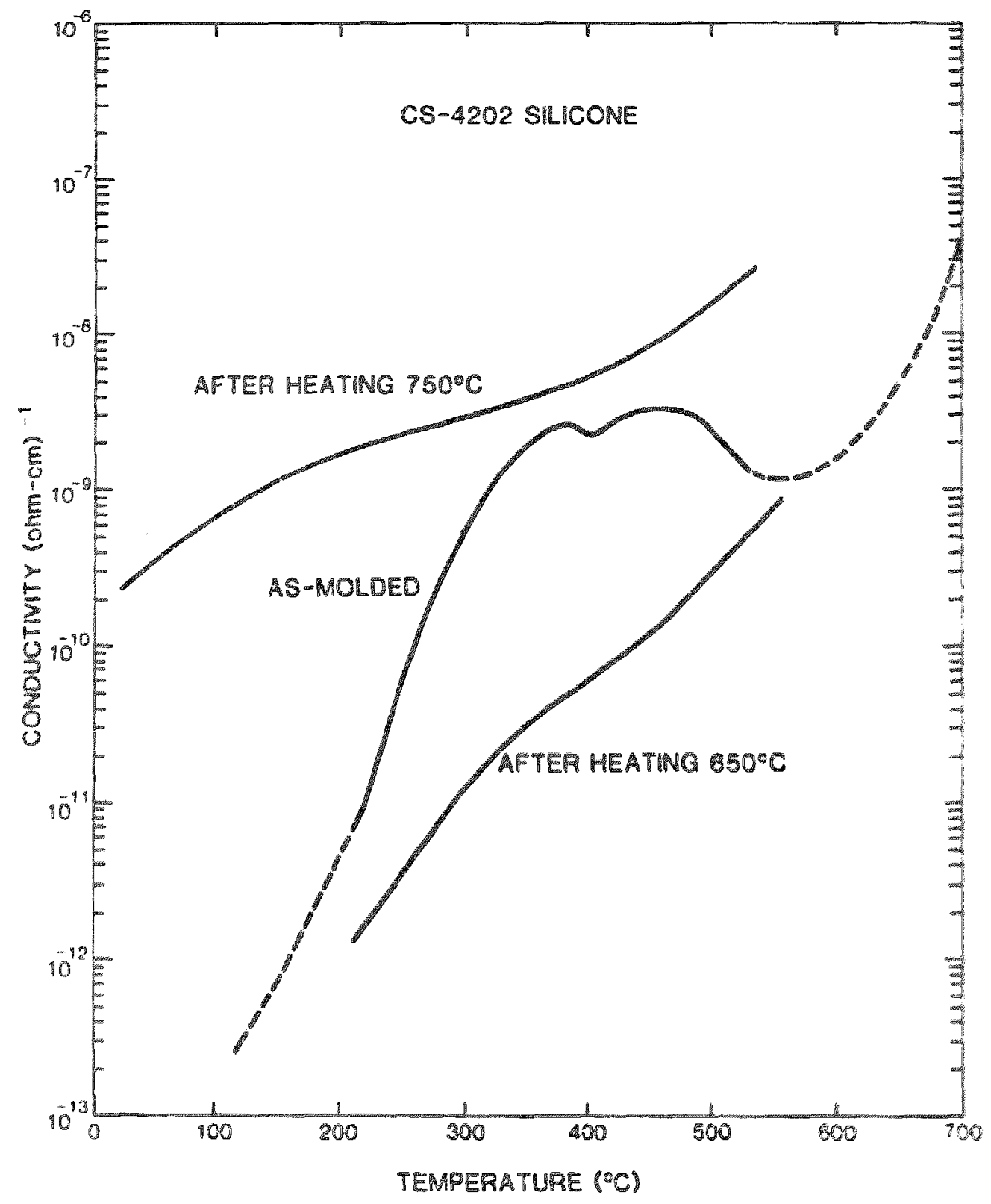

Figure 17. Conductivity temperature dependerce for sistone gless composite. CS-4202 material: waprepered and after temperature cycling to $4650^{\circ} \mathrm{C}$ and to $2750^{\circ} \mathrm{C}$. Dashed portion of curves denotes ronohmic regions. 
The conductivity data for DC-302 (Fig. 15) show slight irregularities (peaks) in the as-molded material at temperatures of $2320^{\circ} \mathrm{C}$ and $2450^{\circ} \mathrm{C}$. After cycling to $4700^{\circ} \mathrm{C}$ the $10 \mathrm{~m}-$ temperature conductivity is further reduced and conductivity peaks are eliminated. Although the conduction above us $40^{\circ} \mathrm{C}$ is slighty higher than for the as-molded materials, this material remains a farly good insulator. Further pyrolysis, however is expected to increase the conductivity.

The conductivity temperature dependence for BRP-50201 in the as-molded state and after temperature cycling to $16500^{\circ} \mathrm{C}$. shown in Fig. 16. In the as-molded material. conducturty pas appear at $250^{\circ} \mathrm{C}$ and $40^{\circ} \mathrm{C}$. These peaks are silghty more prow mounced than those for the anolded DC-302. The perkere are removed after temperteure cycing to $2650^{\circ} \mathrm{C}$. As tor Do-30z. this material remains tarly ingulating, at least in the low temperature range ater cyclying to $450^{\circ} \mathrm{C}$.

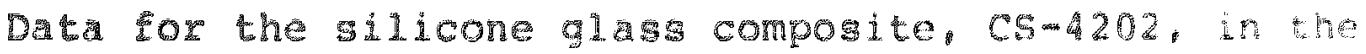

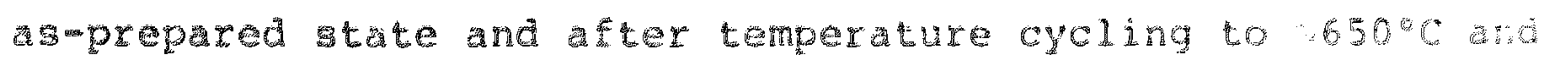
$750^{\circ} \mathrm{C}$ are shown in Fig. 17. In the as-prepared material the value of the conductivity below $250^{\circ} \mathrm{C}$ is the lowest obserev Eor the as-prepared materials. However there are two conductivity peaks at $3980^{\circ} \mathrm{C}$ and $450^{\circ} \mathrm{C}$. Data above $600^{\circ} \mathrm{C}$ show conductivity increases with temperature which are similar to those for the phenolics above $4500^{\circ} \mathrm{C}$ (see Fig. 18). Feter cycling to $650^{\circ} \mathrm{C}$, the conductivity is significantly reduced indicating that the material in this state is good imsulat. After cycling to $2750^{\circ} \mathrm{C}$, however, the conductivity is 
significantly enhanced, with resulting conductivity values much greater than for the as-prepared material. In this state the material is probably carbonized.

The conductivity data for an as-prepared silicone (CS-4202) and phenolic (MXB-71) material are plotted in Fig. 18. Comparing these results helps illustrate some of the differences between these two classes of materials. Specifically, the silicones have lower conductances in the low temperature region below $300-350^{\circ} \mathrm{C}$ ) and exhibit less pronounced conductivity peaks and deviations from ohmic behavior than the phenolics. Other data have shown that as the material pyrolyzes, with heating to $4500^{\circ} \mathrm{C}$ for the phenolics and $2650^{\circ} \mathrm{C}$ for the silicones, the conductivity peaks are eliminated and the low temperature conductivity is reduced (i.e., the materials are better insulators). At higher temperatures, however, the material carbonizes and a conductive material is formed. For the silicones thas occurs at tempratures $100-150^{\circ} \mathrm{C}$ higher than for the phenolics.

V. THERMAL RESULTS

Thermal analysis experiments were performed on the same materials used in the electrical conductivity experiments. The thermogravimetric results are presented in terms of weight loss from heating in both air and nitrogen environments and are given in Table 1. The two different techniques employed gave similar results. The differences can be explained by measurement precision or time at temperature.

The observed masses and relative intensities obtained from the mass spectroscopy experiments are given in Appendix B. 


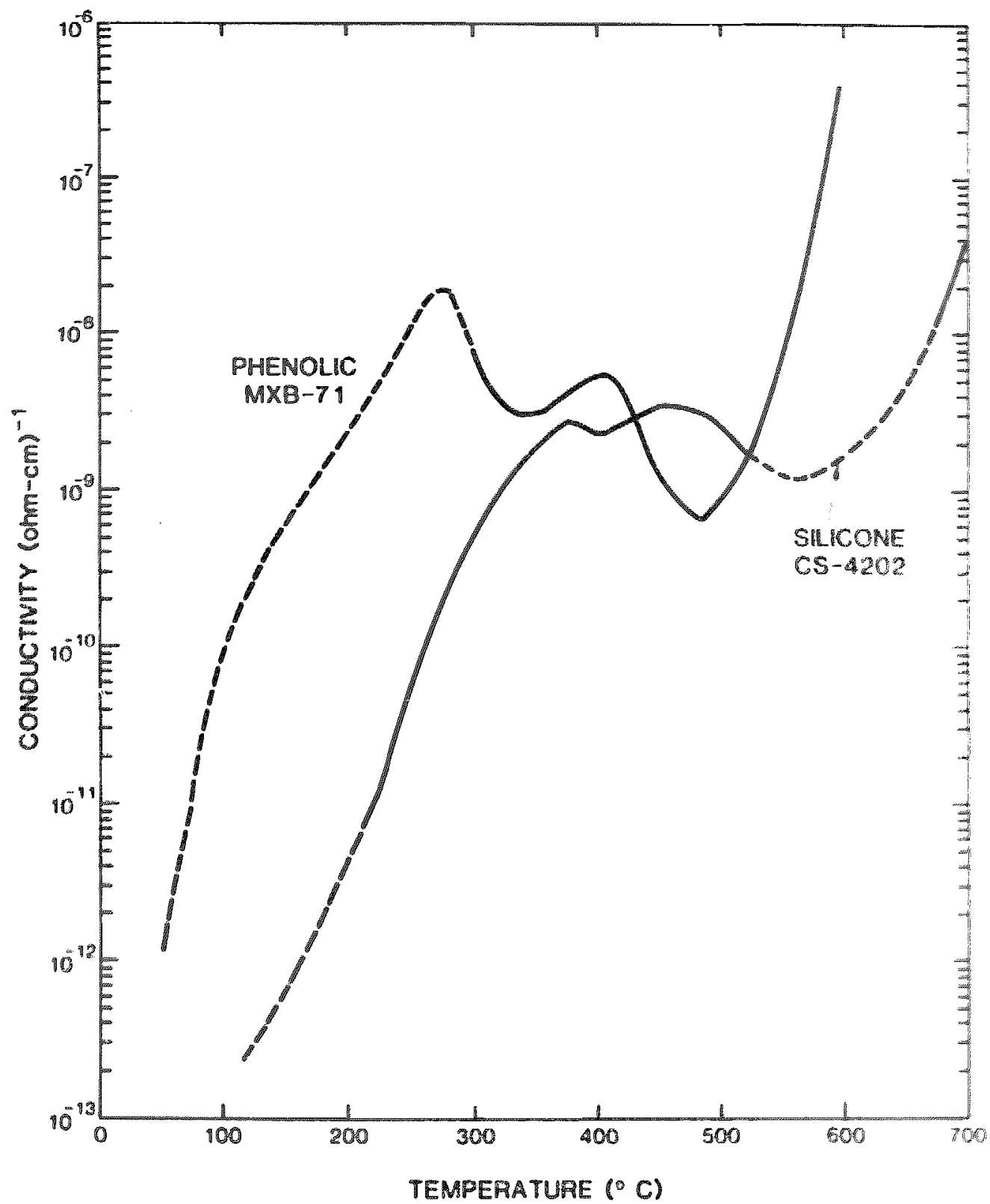

Figure 18. Conductivity temperature dependence tor asmopur. phenolic (MXB-71) and silicone (CS-4202) materis. Data are compiled from results in previous and show that the silicone materials are bet high temperature insulators than the phorolis. 
The spectra presented were chosen to illustrate significant changes with temperature. other spectra were obtained but are not presented. In all of the mass spectra taken, the low temperature spectra $\left(100^{\circ} \mathrm{C}\right)$ are dominated by backgroun peaks particularly at masses 16 to 18,28 and 32 due to the presence of $\mathrm{H}_{2} \mathrm{O}, \mathrm{N}_{2}$, and $\mathrm{O}_{2}$ in the spectrometer. The intensities of the peaks at higher temperature are one or two orders of magnitude greater than background.

The weight loss data on the phenolic FM-5135 show significart mass $10 s 5 e s$ above $100^{\circ} \mathrm{C}$ with values approabing $10-14$ w. $^{2}$ at $600-700^{\circ} \mathrm{C}$ in nitrogen. A larger loss occurs in ar. The mass spectra for FM-5135 (Table B-1, Appendis B) containg boch wate: (masses 16 to 18$)$ and ammonia (masses 14 to 17$)$ below $377^{\circ}$. Both phenyl groups (mass yy) and possibly some alky amine fragments (masses arount 45) are also present. At hicher temperatures the peaks rom 30 to 4 could be explatred by the presence of methy and amethylamine fragnents. Whe pers a $76-78,90,93$, and 106 ind 2 ate the presence of a crest. A proposed cromginked phenolic structure is show in tale 2. Several possible molecular fragments are given in Tables 2 and 3.

The MXB-71 phenolic also exhibits significant, mass losses above $100^{\circ} \mathrm{C}$, with the loss in air greater than that in ${ }^{k}{ }^{*}$ The mass spectra of $M \times B-71$ (Table $B-2$, Appendix 3 ) ars dominated by water below $300^{\circ} \mathrm{C}$. Also important are both phenyl groups and possibly some alkylamine fragments which ca. oxplain the large peaks around 31 and 45 . The presence of 


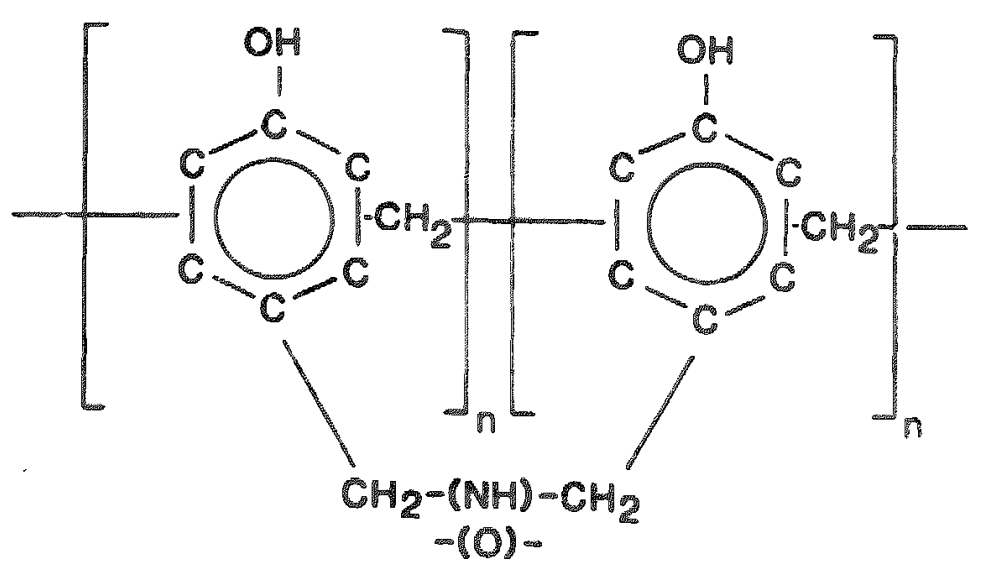

PROPOSED

FRAGMENT

\begin{tabular}{llr}
\hline $\mathrm{NH}_{3}$ & (AMMONIA) & 17 \\
$\mathrm{CH}_{3} \mathrm{NH}_{2}$ & (METHYLAMINE) & 31 \\
$\mathrm{C}_{3} \mathrm{H}_{2}$ & & 38 \\
$\mathrm{CHNC}_{2} \mathrm{C}_{3} \mathrm{H}_{3}$ & & 39 \\
$\mathrm{CH}_{2} \mathrm{NC}$ & & 40 \\
$\mathrm{CH}_{2} \mathrm{NCH}$ & & 41 \\
$\mathrm{CH}_{2} \mathrm{NCH}_{3}$ & & 43 \\
$\mathrm{CH}_{3} \mathrm{NHCH}_{3}$ & (DIMETHYLAMINE) & 45 \\
$\mathrm{C}_{6} \mathrm{H}_{5}$ & (PHENYL) & 77 \\
$\mathrm{C}_{6} \mathrm{H}_{6}$ & (BENZENE) & 78 \\
$\mathrm{C}_{6} \mathrm{H}_{5} \mathrm{CH}_{2}$ & (BENZYL) & 90 \\
$\mathrm{C}_{6} \mathrm{H}_{5} \mathrm{O}$ & (PHENOXY) & 93 \\
$\mathrm{C}_{6} \mathrm{H}_{4} \mathrm{CH}_{2} \mathrm{O}$ & (CRESOL) & 106
\end{tabular}




\section{TABIE 3}

Proposed Mass Spectrometer Fragments for FM-5135 Bhenolic

Fragment

Water

Arnmonia

Alylamines

Prengl

5henol

Cresol

\begin{tabular}{lcc}
\multicolumn{3}{c}{ Relative Intensity } \\
\hline $78^{\circ} \mathrm{C}$ & $\frac{317^{\circ} \mathrm{C}}{80}$ & $\frac{350^{\circ} \mathrm{C}}{35}$ \\
350 & 80 & 100 \\
18 & 13 & 57 \\
26 & 4 & 60 \\
- & - & 28 \\
- & - & 51
\end{tabular}

TABLE

Proposed Mass spectrometer Framents for MX-71 Phemolio Relative Intensity

\begin{tabular}{|c|c|c|c|}
\hline Fragment & $110^{\circ} \mathrm{C}$ & $225^{\circ} \mathrm{C}$ & $300^{\circ}$ \\
\hline Water & 100 & 51 & 63 \\
\hline Akylamines & 11 & 100 & 6 \\
\hline Pheny 1 & 11 & 2 & 45 \\
\hline Phenol & - & 2 & 45 \\
\hline Cresol & - & 2 & 100 \\
\hline
\end{tabular}


amine groups is also indicated by the intensities from masaes 14 to 17. At higher temperatures the presence of peaks at inasses $78,90,93$ and 106 indicate the presence of a cresol (see Tables 2 and 4 ). Peaks observed at masses 38 and $i 9$ could be explained by fragmentation of the phenyl groups. was confirmed by taking a spectrum at a reduced electron bear: energy of $30 \mathrm{eV}$. The intensities of the peaks at masses 38 and 39 decreased relative to the intensities of the mass pears at 106 and 121. This indicates that the species at masses 106 and 121 are parent ions and the ones at 38 and 39 axe fracments. The thermal analysis for silicone-based bC-302 shows :-: similar behavior in air and flowing $\mathrm{N}_{2}$ with a slightly large: mass loss in air. The weight loss is less than for the phenclics, especially below $2500^{\circ} \mathrm{C}$. The mass spectrometrio results (Table $\mathrm{B}-3$. Appendix B) indicate that below $300^{\circ} \mathrm{C}$ the major loss is due to water (mass 18).

Since toluene was used as a solvent in these resins it possible that the mass at 91 is due in part to $C_{7} H_{7}^{4} 1181$. The mass at 77 is due to a phenyl group. The masses at ol an: 107 are probably due to $\mathrm{SiO}_{3} \mathrm{CH}_{3}^{+}$and $\mathrm{SiO}_{4} \mathrm{CH}_{3}^{+}$fragments. The from 26 to 29 are an indication of ethyl groups. The pears around 40 to 45 could be due to methyl-silicone groups ares possible siot at 44 . At higher temperatures the phenyl peak dominates the spectra (with phenyl fragments at masses $3 ., 30$ and 49-55). Heavier unidentified molecules with masses wo 153 are also present at high temperatures. Tables 5 and 6 contain a proposed silicone resin structure and severa pos fragments. 
TABLE 5

Proposed Structure for Silicone Resins

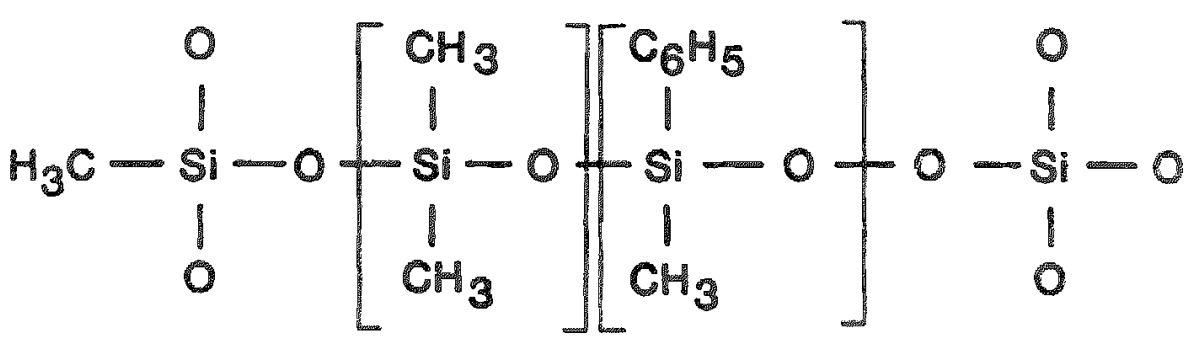

\begin{tabular}{lc}
$\begin{array}{l}\text { PROPOSED } \\
\text { FRAGMENT }\end{array}$ & MASS \\
\hline $\mathrm{SiCH}_{3}$ & 43 \\
$\mathrm{SiO}$ & 44 \\
$\mathrm{C}_{6} \mathrm{H}_{5}$ & 77 \\
$\mathrm{SiO}_{3} \mathrm{CH}_{3}$ & 81 \\
$\mathrm{SiO}_{4} \mathrm{CH}_{3}$ & 107
\end{tabular}


TABLE 6

Proposed Mass Spectrometer Eragments for DC-302 Silicone

Eragment

$\begin{array}{lccc} & 117^{\circ} \mathrm{C} & 230^{\circ} \mathrm{C} & \frac{360^{\circ} \mathrm{C}}{15} \\ \text { Water } & 100 & 100 & 84 \\ \text { SiCH }_{3} & 28 & 25 & 43 \\ \text { SiO } & 31 & 17 & 100 \\ \text { PhenY1 } & 11 & 29 & 15 \\ \text { Toluene }_{\text {SiO }} \mathrm{CH}_{3} \text {; } & 33 & 41 & 1 \\ \text { SiO }_{4} \mathrm{CH}_{3} & 13 & 1 & 1\end{array}$

TAELE 7

Proposed Mass Spectrometer Fragments for BRP-50201 11 icone

Fragment

Water

$\mathrm{SiCH}_{3}$

sio

Pheny 1

Toluene)

$\mathrm{SiO}_{3} \mathrm{CH}_{3}$ )

$\mathrm{SiO}_{4} \mathrm{CH}_{3}$
Relative Intensity

$110^{\circ} \mathrm{C}$

6

$350^{\circ} \mathrm{C}$

2

11

2

1

3

100

100

3

3 
TABLE 8

Proposed Mass Spectrometer Fragments for CS-4202 Silicone

Fragment

$\mathrm{SiCH}_{3}$

SiO

Pheny 1

Toluene)

$\left.\mathrm{SiO}_{3} \mathrm{CH}_{3}\right)$

$\operatorname{SiO}_{4} \mathrm{CH}_{3}$
Relative Intensity

$202^{\circ} \mathrm{C} \quad 375^{\circ} \mathrm{C}$

12

1

14

16

8

37

100

3

2 
The BRP-50201 silicone material also loses weight $z \mathrm{~m}^{\circ}$ slowly until above $500^{\circ} \mathrm{C}$ with the largest loss in air betweer: $500-600^{\circ} \mathrm{C}$. The mass spectra (Table B-4. Appendix B) at 10 . temperatures show very little water loss (see also Table 7). The largest peak, which occurs at 91 , is probably due to $\mathrm{SiO}_{3} \mathrm{CH}_{3}^{+}$or the toluene solvent [20]. The high temperature spectra are dominated by the phenyl peak at mass 77 and fragments at 38,39 , and 50-52. The peaks at masses 40 to 4. could be due to methyl-silicone groups. The spectra for BRP-50201 indicate the presence of large molecules with masses up to 280 .

The silicone-glass composite, CS-4202, lost only minur amounts of material up to $2500^{\circ} \mathrm{C}$. As with other samples, more material was logt in air than in $\mathrm{N}_{2}$. The mass spectra (Table B-5, Appendix B) indicates that only minor amonnts 0 : water were 1ost (see also Table 8 ). The peak at masses 38 . 39, 50-52 and 77 indicates the presence of phenyl grouss. The peaks for masses 40 to 43 could be due to methy wilicon. entities.

Several comparisons can be made between these materiais. The silicone-based materials (aklyl-phenyl-silicone composites. had much better thermal stability than the phenolics frith phenolic and amine based constituents). The silicone-glass composite CS-4202 was the most stable material because At 105 the least amount of weight at high temperatures. All the materials lost more weight in air when compared to the weight loss in $\mathrm{N}_{2}$. The MXB-71 and FM-5135 phenolics were the loast stable in air and $\mathrm{N}_{2}$. The mass spectra of MXB-71 ard F:-3:3 were similar. Both materials probably contain amines and phonols. 
The FM-5135 spectra between $200-300^{\circ} \mathrm{C}$ were dominated by the loss of $\mathrm{NH}_{3}$. AIl of the materials except the BRP-50201 and cs-4202 silicones lost a large amount of water. At the higher temperatures all the spectra indicated the presence of heavier molecules but the spectra for BRP-50201 had mojecules with molecular weights that were 100 to 150 mass units larger than any of the other materials.

VI. CORRELATION OF ELECTRICAI AND THERIAL RESULTS

Certain correlations can be made between the electrical and thermal characteristics. For the phenolics. FM-5135 and MxB-71, the mass 1038 which occurs between 200 and $300^{\circ} \mathrm{C}$ (water and/or ammonia and amines) correlates with the conductivity peak at $250-270^{\circ} \mathrm{C}$ (see EIgs. 19 and 20). Ma the temperature is increased and volatilization occurs, the masem rial exhibits a decrease in the conductance (above $250-270^{\circ} \mathrm{C}$ ) which produces a perk in the conductivity temperature dependronc As the temperature is further increased the loss of othat mas species occurs (phenolic and amine groups and higher molecular weight species) and results ir a second peak in the conductivity at $2400^{\circ} \mathrm{C}$. The position and magnitude of these peaks are expected to vary with heating rate. As the material pyrolyzes with heating to $2500^{\circ} \mathrm{C}$, the conductivity peaks are eliminated and the low temperature conductivity is reduced (i.e. the materials are better insulators). At higher temperatures. however, the material carbonizes and becomes conductive.

The silicone materials DC-302, BRP-50201, and CS-4202 have much better stability and are better insulators than the phenolics. 


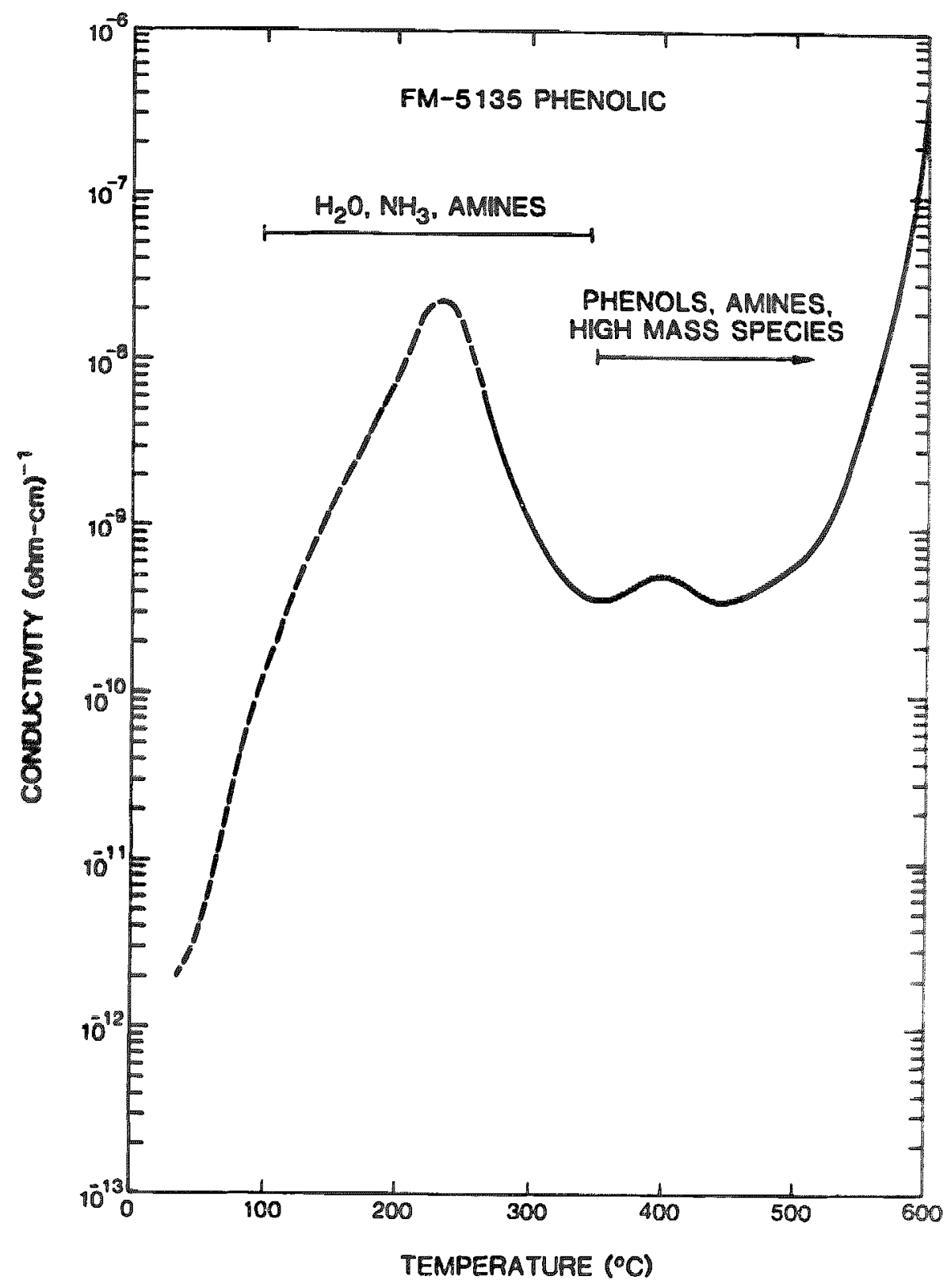

Figure 19. Correlation of temperature dependence of electrical conductivity peaks and major thermal decomposition products for FM-5135 phenolic. 


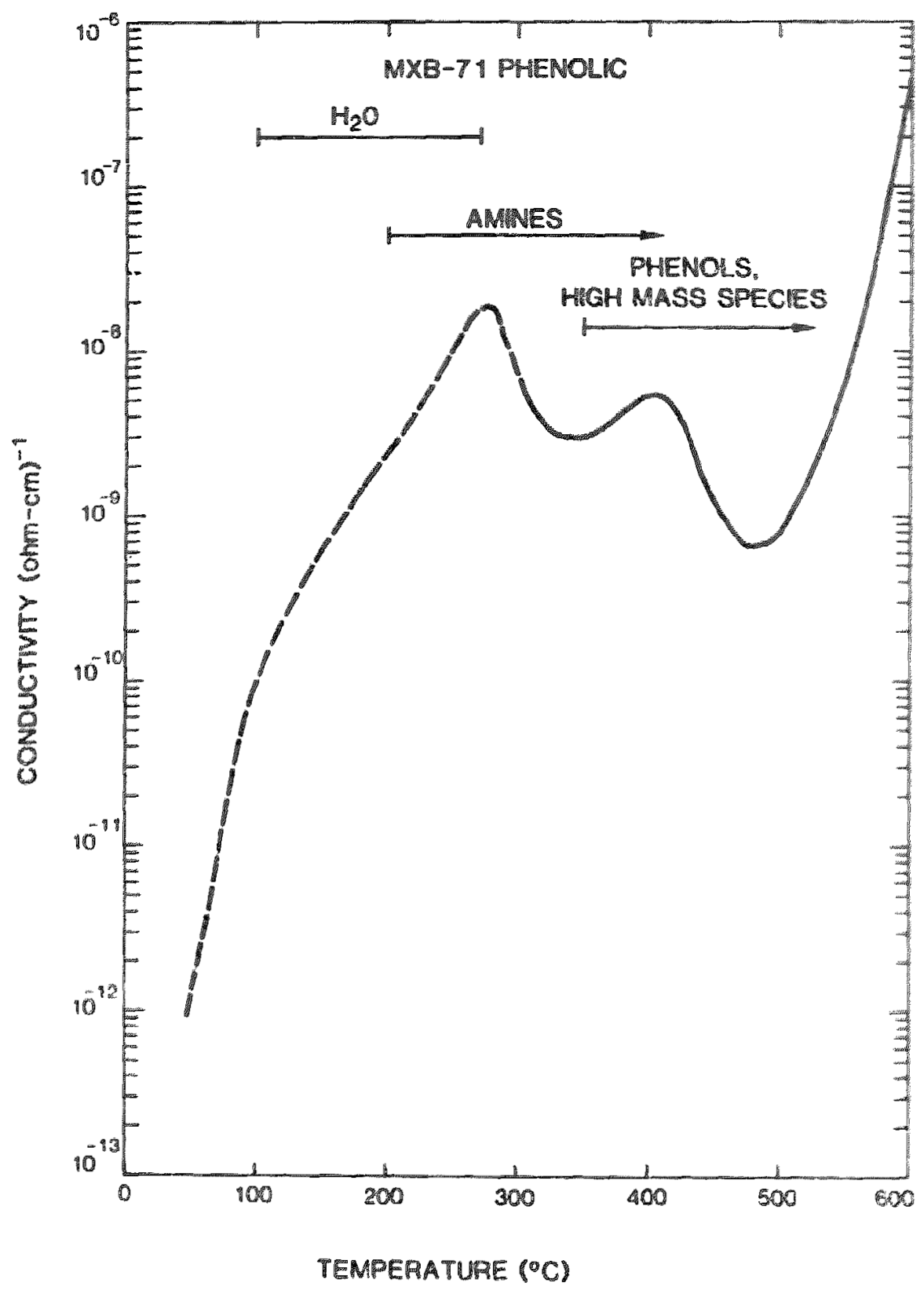

Figure 20. Correlation of temperature dependerce of electrical conductivity peaks and major thermal decomposition products for MXE-7! phenolic. 
They exhibit less mass loss, have lower conductivities in the Low temperature region (below $300-350^{\circ} \mathrm{C}$ ), and exhibit less pronounced conductivity peaks and deviations from ohmic behavior (see Figs. 21-23). The CS-4202 silicone is the most stabie of the materials examined and is the best insulator below $-2500 \mathrm{c}$. At the higher temperatures, the silicones lose both alkyl-silicche and phenyl groups as well as high molecular weight polymers. As for the phenolics, the changes in conductivity correlate with outgassing and/or decomposition of the material. Conducting peaks are eliminated after pyrolysis upon temperature cycing ch postcuring. The conductivity decreases with pyrolysis upon heating the silicones to $600-650^{\circ} \mathrm{C}$ (phenolics to $50^{\circ} \mathrm{C}$ ). Upon heating to higher temperatures the material carbonizes anc the conductivity increases in manner which is relatively independent of the starting material or previous postcure conditions $[5,9]$

Deviations from ohmic behavior in all of these meterais appear to be most pronounced when the material is not in a state of equilibrium. At low temperature in the insulating state nonohmic behavior may be due to outgassing or other material or contact properties. At higher temperatures, however, the nonohmic behavior appears to be associated with non-equilibrium effects related to decomposition and/or outgassing. 


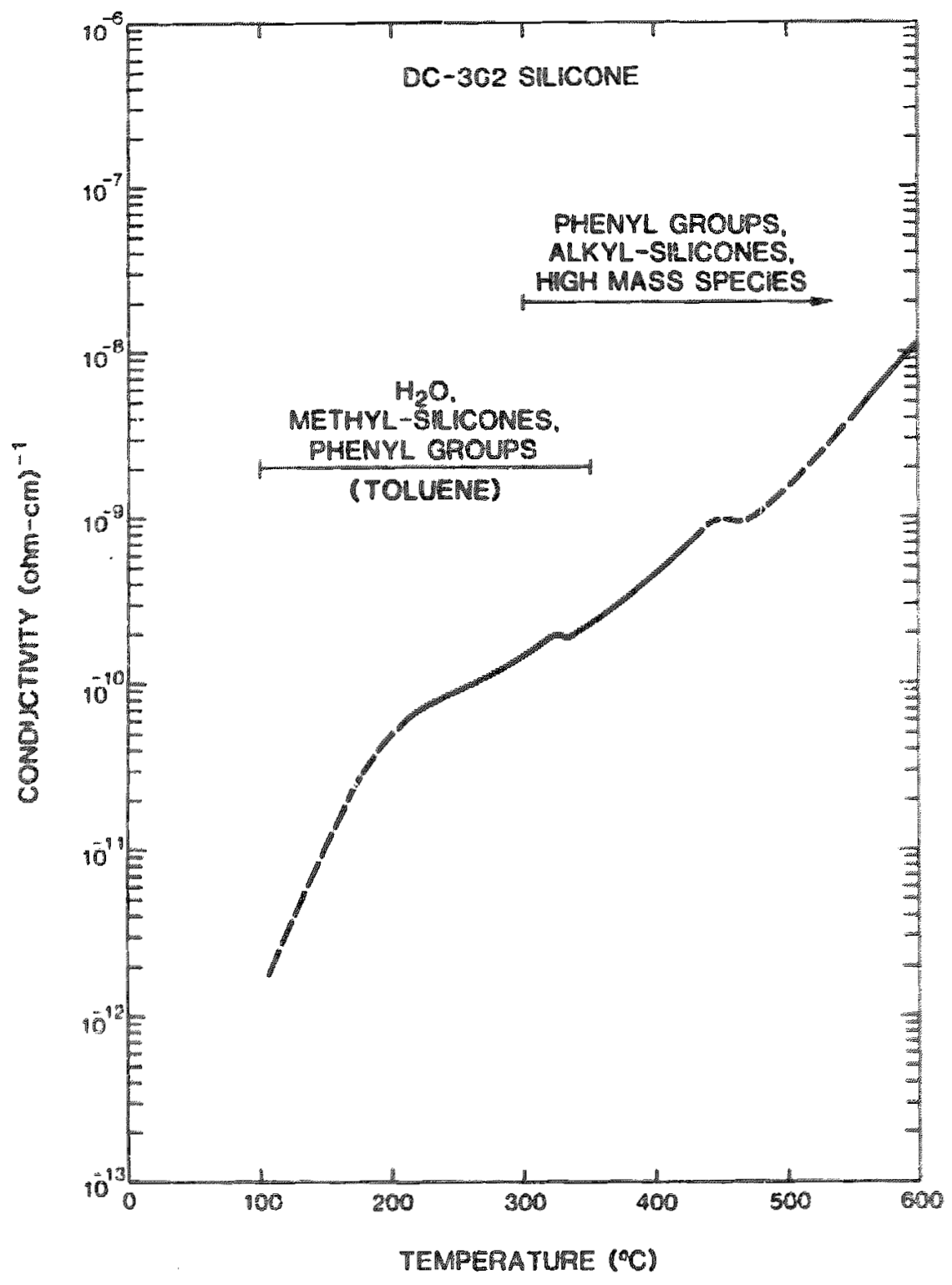

Figure 21. Correlation of temperature dependerce of electrical conductivity peaks and major thermal decomposition products for $D C-302$ silicone material. 


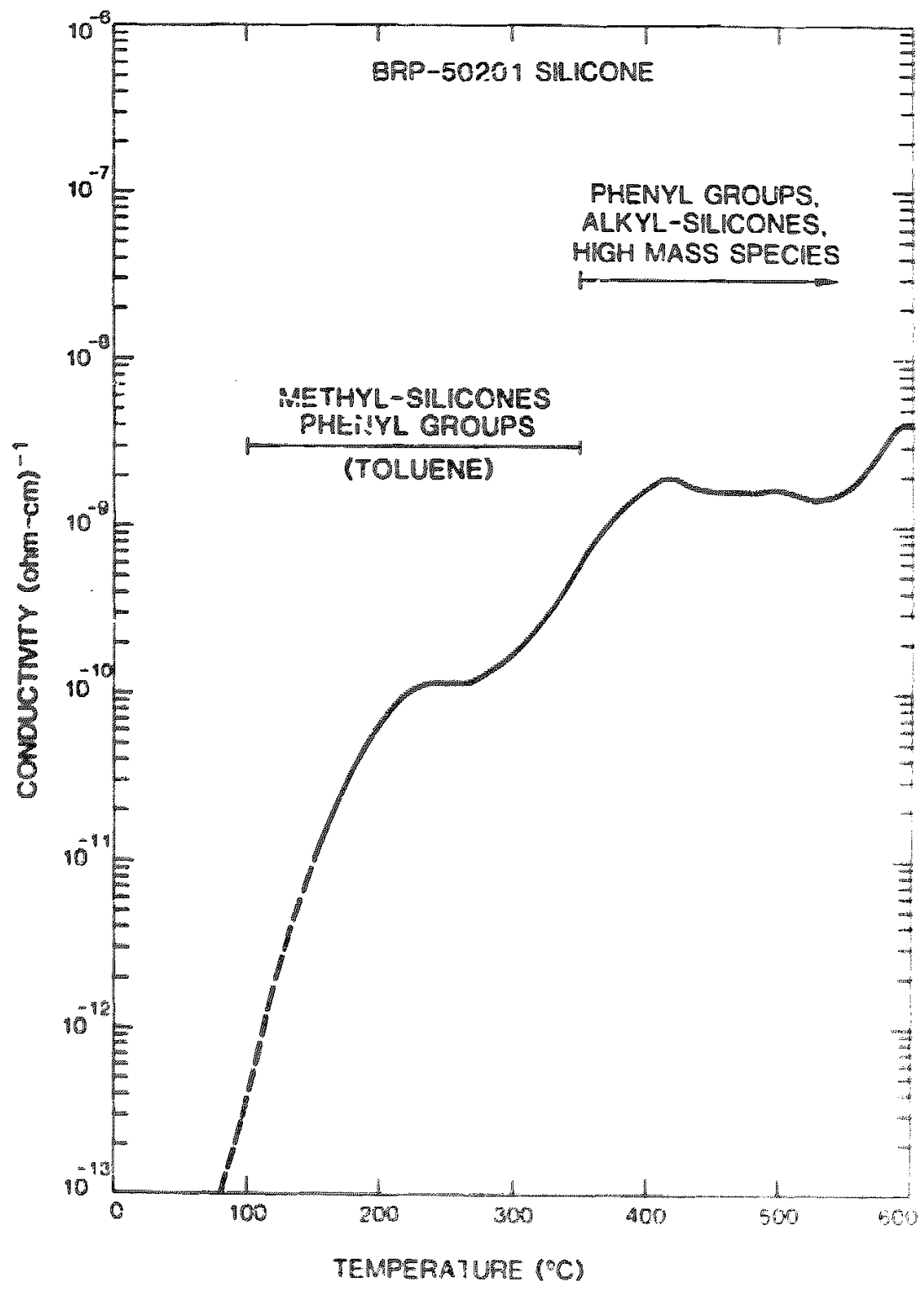

Figure 22. Correlation of temperature dependence of electrical conductivity peaks and thajor thama decomposition products for BRP-5020 silichom material. 


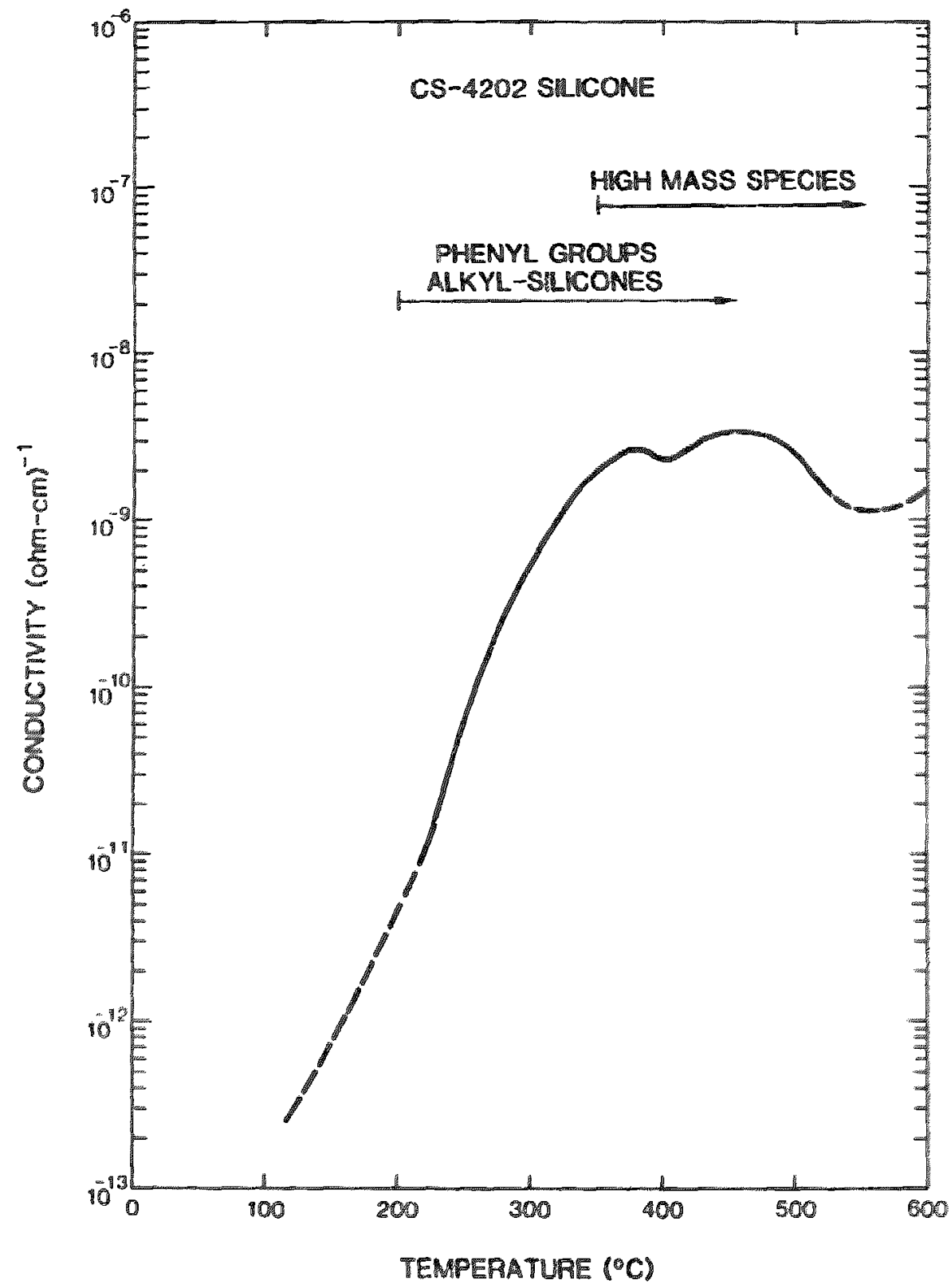

Figure 23. Correlation of electrical condugtivity peate and thermal decomposition products for the silicone-glass composite, CS-4202. 


\section{CONCIUSIONS}

These experiments show a direct correlation between thermal stability and temperature dependent electrical conduction characteristics in silicone- and phenolic-bassd materials. Peaks in the conductivity ard deviations from ohmic conduction correlate with decomposition and the loss of volatiles from the material. The excellent correiation between thermal and electical properties suggests that electrical conductivity can be used as a thermal analysis tool in characterizing these materials.

These studies have also shown that the conductance is relatively independent of electrode material. surface conduction, polarization efects, and voltage polarity and magnitude. This suggests that in these ewperiments a bir property of the material (conductivity) has been measured. Furthermore, the nature of the conductivity appears to be principally electonic in character especially in the pout curea anc carbonized naterial. It seems reasonabe, hownt. to expect some ionic character to the conductivity espedin. during oubgassing and/or decomposition.

The application of these materials to firesets must include consideration of structural as well as electrid characteristics. Whereas postcuring can improve the lectrical insulating characteristics at low temperature. It must be recognized that such postcures may adversely difect the structural properties. All of these factors must be taken into account in selecting materials, processing partat... and postcure conditions for high temperature applications. 


\section{ACKNOWLEDGEMENTS}

0. (Buzz) Milton is credited with having initiated these studies and for having provided the instrumentation and preliminary data. G. I. Cessac, E. A. Salazar and $\mathbb{R}_{\text {. }}$ iirschbuehler provided the test materials and supplied information and guidance regarding materials properties. The molded materials were obtained from Bendix. Ransas City. E. A. Salazar and G. I. Cessac coordinated the overall effor between Bendix, Kansas City and Sandia National Laboratores in Albuquerque. J.H. Lair and F. F. Francis assisted in al phases of the experimental work. J. C. Lanove and C. S. Casaus conducted some of the thermogravimetric analysis measuremes. C. E. Robinson assisted with some of the themal weasurements. C. Armold and t. A. Harah made valuable contributions to understanding the chemistry of decomposition. 
IX. REFERENCES

1. B. G. Martin, Materials Evaluation 35, 48 (1977).

2. G. W. Lawless, Polymer Engineering and science 20. $546(1980)$.

3. Z. N. Sanjana, in International Conference on Polymer Processing (MIT Press, Cambridge, MA, 1977), p. 827.

4. B. G. Martin, Materials Evaluatior 3449 (1976).

5. S. Mrozowski, physical Review 85, 609 (1952).

6. H. A. Pohl and S. I. Rosen, in Proceedings of the Fituh Conference on Carbon, volume 2 Pergamon Fress Inc. New York, 1963) p. 113 .

7. W. D. Brennan, J. J. Brophy, and H. Schonhorn, in Organic Semiconductors - Proceedings of an Inter-Industry Conference. (Editors J. J. Brophy ard J. W. Buttrey, The Macmillan Company, New York, 1962) p. 159.

8. D. E. Weiss and B. A. Bolto in physics and Chemistry o: the organic solid state volume II. (EdS. D. Fox. \%. Wabes. and $\mathrm{A}$. Weissberger, Interscience Publishers, $1965 \mathrm{p}, 6 \%$

9. I. A. Harrah, Sandia National Laboratories, Memorandum on Electrical Conductivity of Polymers, March 9, 1972 ).

10. L. A. Harchey, Sandia National Laboratories, Internal Memorandum on High Temperature Tests on Encapsulants and Molding Compounds (S. D. Spray to Distribution) Jnne $19 \%$.

11. G. Voida, Sandia National Laboratories, Interna I Memoram on Surface and Volume Resistance Measurements of clad Laminates in Abnormal Environments, November 1971.

12. S. I. Madorsky. Thermal Degradation of organic Polymers. (John Wiley and Sons, Inc., 1964) P. 288.

13. D. W. Van Krevelen and P. I. Hoftyzex, Properties of Polymers (Elsevier Scientific Publishing Company, New York, 1976 ) p. 459.

14. J. A. Brydson, Plastics Materials, Third Edition (Newnes-Butterworths, London, 1975).

15. W. Brenner, D. Lum, and M. W. Riley, High-Temperature Plastics (Reinhold Publishing Corporation, Nen Tork. 1962) pp. 53, 160 . 
16. G. W. Griffith, Bendix, Kansas City Division, Internal Memorandum on The Characterization of 91 id Phenolic Resir, LTG 337221 , May 1978.

27. G. W. Griffith, Bendix, Kansas City Division, Internad Memorandum on the Characterization of MXB-71 Phenolic Resin, December 1978.

13. S. L. DeGisi, Bendix, Ransas City Division Internal Quarterly Report on Evaluation of High Temperature Molding Compounds, PDO 6984980, December 1975.

19. R. E. Trujillo, Sandia National Laboratories Report SAND80-2514, January 1981 .

23. J. W. MCFarland, Eendix, Kansas City Division Quarterly Report on Development and scale-Up of a BRC Silicone Molding Compound, PDo 06985170. April 1978.

21. K. R. Hirschbuehler, Sandia National Laboratories Peport. SRND81-1794, 1981. 


\section{APPENDIX A \\ FOUR-TERMINAL CONDUCTIVITY EXPERIMENTS}

Four-terminal conductivity experiments were pursued or the FM-5135 phenolic. The sample and electrode configuritor. is shown in Fig. A-1. The current electrodes were across the ends of the sample, whereas the voltage electrodes contacted only the surface regions surrounding the specimen near the center of the sample. The samples were cut from the same $2 . s i s$ as used for the two-terminal experiments. Current filow was in the plane of the disk, in contrast to the two-terminal expe:ments where current flow was normal to this plane. In order to avoid electrical leakage through the sample holder, the sample and electrical leads were suspended within the sump chamber, as indicated in ig. A-2. The sample chamber sury as a thermal mass around the specimen in which a thermocont was mounted. The sample and thermocouple temperature wo the same. The sample leads were supported out ide tho hot ac

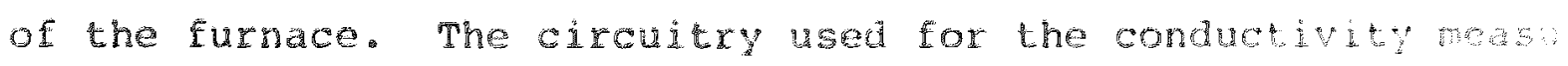
ments is shown in Fig. A-3. For these experiments the voltare across the sample was $300 \mathrm{~V}$.

During the first cyele to high temperature the vol taw drop across the voltage electrodes had an unempected $y$ ich value and was nonohmic. However, the current-voltage characteristics obtained using the contacts at the onde of specimen were very similar to those for the two-teminal experiments of Fig. Ia in the text. An explanation for this behavior can be given in terms of differences in surface and 


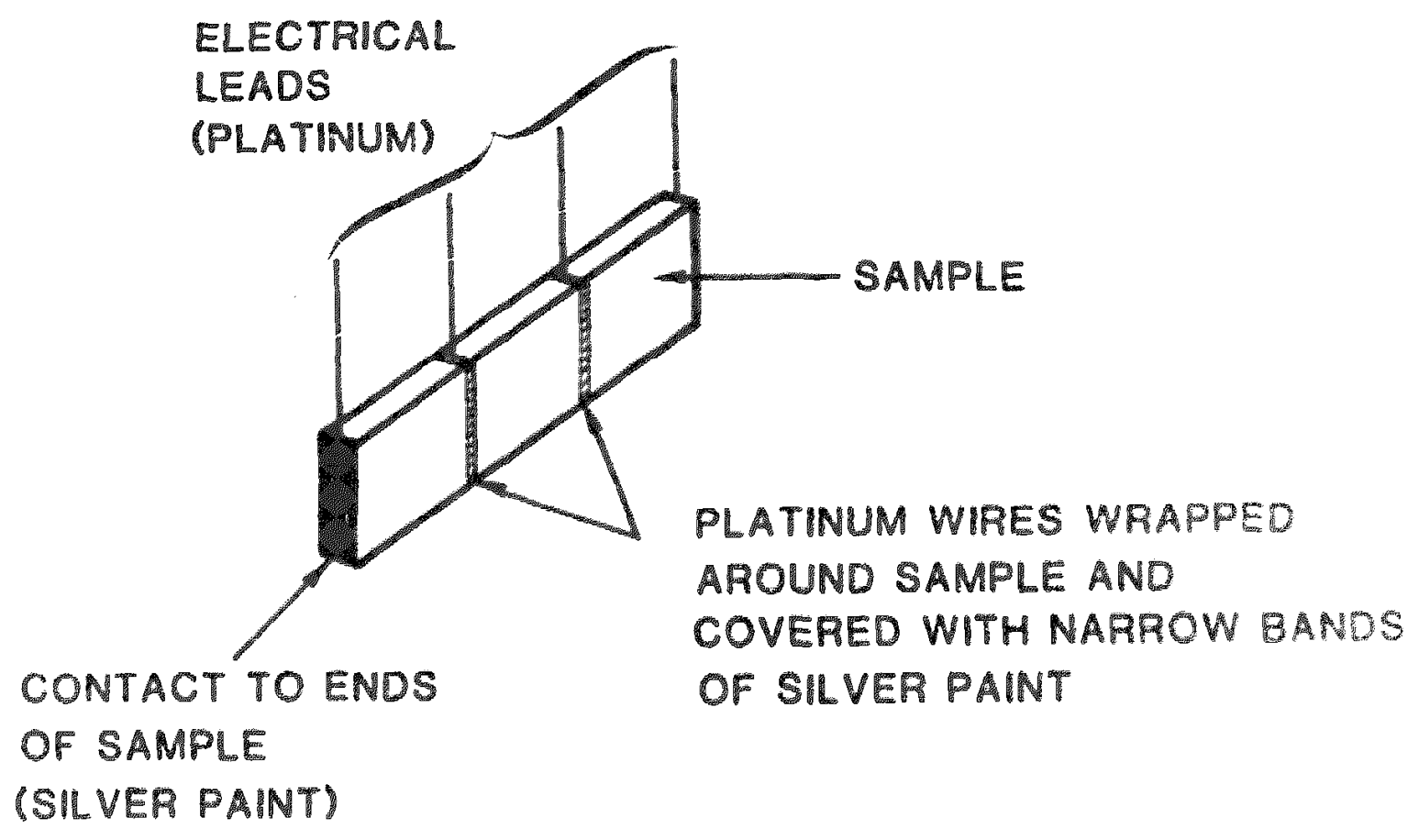

Figure A-1. Four-terminal electrical conductivity sumple do electrode conizuration. 


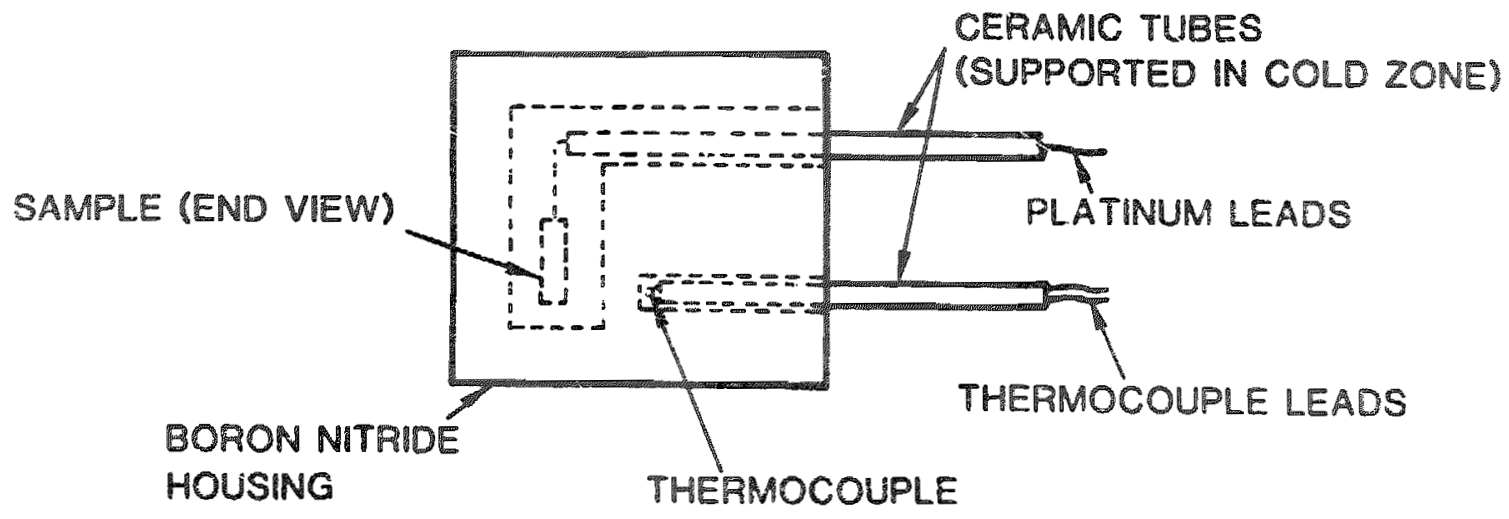

Eigure A-2. Sample holder configuration for four-texminal electrical conductivity experiments.

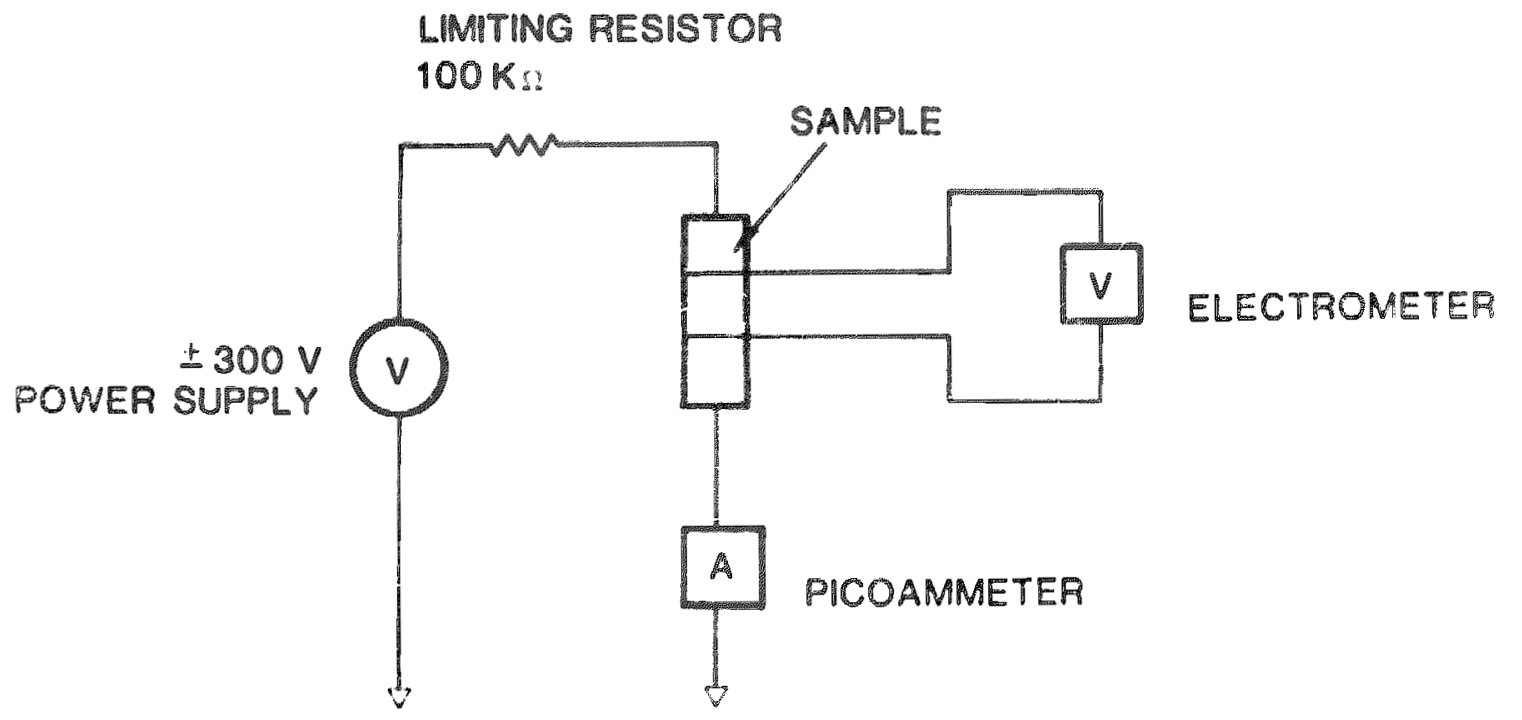

Figure A-3. Circuit schematic for four-terminal electrical conductivity measurements. 
bulk conduction. Specifically, during decomposition the surface may become resistive at a more rapid rate than the bulk materia. In this situation, the voltage contacts to the surface do not give an accurate measurement of a bulk property. This suggestion is consistent with results obtained upon postcuring where reductions in conduction are observed after volatile constituents are lost from the material. After the sample pyrolyzes upon cycling to high temperatures $\left(2600^{\circ} \mathrm{C}\right)$, the voltage measured using the voltage electrodes on the surface was as expected for a sample where the surface and the bulk of the material were in egulibrium. Although more experiments need to be conducted in order to fuIIy understand these effects, it does appear that during decompostion that the surface of the material may become resistive more rapidy than that of the bulk material. This would imply that the actroce area of coverage and positioning on the sample is importan in these experiments. In order to obtain the results observed in the two-terminal experiments of Fig. 1a, the loss of volatiles from the material under the electrodes during decomposition probebly occurred at a rate slower than that from material in an unelectroded area. Thus, the electrode configuration may influence the rate dependence of the effects observed in these experiments. 
XI. APPENDIX B

MASS SPECTRA RESULTS

Observed masses and relative intensities as a function oz temperature from mass spectrometer experiments on phenolic anc. silicone materials.

Table B-1: FM-5135 Phenolic

\begin{tabular}{|c|c|c|c|}
\hline \multicolumn{2}{|c|}{$78^{\circ} \mathrm{C}$} & \multicolumn{2}{|c|}{$317^{\circ} \mathrm{C}$} \\
\hline Mass & Int & Mass & Int \\
\hline 12 & 8 & 12 & 3 \\
\hline 13 & 2 & 13 & 1 \\
\hline 14 & 100 & 14 & 6 \\
\hline 15 & 9 & 15 & 11 \\
\hline 16 & 39 & 16 & 71 \\
\hline 17 & 11 & 17 & 100 \\
\hline 18 & 35 & 18 & 80 \\
\hline 26 & 7 & 25 & 1 \\
\hline 27 & 14 & 26 & 2 \\
\hline 28 & $100+$ & 27 & 7 \\
\hline 32 & 63 & 28 & 31 \\
\hline 37 & 4 & 29 & 8 \\
\hline 38 & 14 & 31 & 7 \\
\hline 39 & 11 & 32 & 2 \\
\hline 40 & 18 & 37 & 1 \\
\hline 41 & 8 & 38 & 3 \\
\hline 42 & 11 & 39 & 1 \\
\hline 43 & 18 & 41 & 3 \\
\hline 44 & 2 & 42 & 3 \\
\hline 49 & 6 & 3 & 5 \\
\hline 50 & 9 & 44 & 7 \\
\hline 51 & 6 & 45 & 12 \\
\hline 52 & 4 & 49 & 1 \\
\hline 54 & 9 & 50 & 1 \\
\hline 55 & 8 & 51 & 1 \\
\hline 56 & 7 & 54 & $\overline{1}$ \\
\hline 57 & 4 & 55 & 1 \\
\hline 62 & 2 & 56 & 1 \\
\hline 66 & 3 & 77 & 4 \\
\hline 69 & 5 & & \\
\hline 73 & 2 & & \\
\hline 77 & 26 & & \\
\hline
\end{tabular}

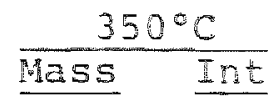

12

13

14

15

16

17

19

25

26

27

28

29

30

37

38

39

40

41

42

43

49

50

51

52

53

54

55

56

62

64

65

76

77

78

90

93

106

121

134 
Table B-2: MXB-71 Phenolic

\begin{tabular}{|c|c|}
\hline \multicolumn{2}{|c|}{$110^{\circ} \mathrm{C}$} \\
\hline Mass & Int \\
\hline 12 & 2 \\
\hline 14 & 15 \\
\hline 15 & 2 \\
\hline 16 & 15 \\
\hline 17 & 72 \\
\hline 18 & $100 \div$ \\
\hline 26 & 2 \\
\hline 27 & 4 \\
\hline 28 & 100 \\
\hline 31 & 2 \\
\hline 32 & 19 \\
\hline 38 & 2 \\
\hline 39 & 6 \\
\hline 40 & 4 \\
\hline 41 & 6 \\
\hline 42 & 4 \\
\hline 43 & 6 \\
\hline 4 & 9 \\
\hline 45 & 6 \\
\hline 50 & 2 \\
\hline 52 & 4 \\
\hline 52 & 2 \\
\hline 55 & 4 \\
\hline 56 & 2 \\
\hline 57 & 2 \\
\hline 77 & 11 \\
\hline
\end{tabular}

\begin{tabular}{|c|c|}
\hline \multicolumn{2}{|c|}{$225^{\circ} \mathrm{C}$} \\
\hline Mass & $\operatorname{Int}$ \\
\hline 12 & 5 \\
\hline 13 & 5 \\
\hline 14 & 18 \\
\hline 15 & 39 \\
\hline 16 & 21 \\
\hline 17 & 89 \\
\hline 18 & $100+$ \\
\hline 24 & 3 \\
\hline 25 & 5 \\
\hline 26 & 29 \\
\hline 27 & 61 \\
\hline 28 & 76 \\
\hline 29 & 58 \\
\hline 30 & 16 \\
\hline 31 & 95 \\
\hline 32 & 18 \\
\hline 37 & 6 \\
\hline 38 & 11 \\
\hline 39 & 34 \\
\hline 10 & 16 \\
\hline 41 & 39 \\
\hline 42 & 39 \\
\hline 43 & 58 \\
\hline 44 & 24 \\
\hline 45 & 100 \\
\hline 46 & 37 \\
\hline 57 & 5 \\
\hline 58 & 5 \\
\hline 59 & 3 \\
\hline 65 & 3 \\
\hline 77 & 3 \\
\hline 93 & 3 \\
\hline 106 & 3 \\
\hline
\end{tabular}

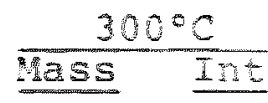

12

13

14

15

16

10

19

25

26

29

28

29

30

31

32

36

37

30

39

40

41

42

43

4

50

51

52

53

54

62

64

65

74

76

78

90

93

103

106

112

121

135

9

36

23

64

5

5

28

3
9

23

100

36

27

$1 \%$

28

27

55

27

3

18

27

27

27

36

45

36

28

9

100

9

45 
Table E-3: DC-302 Silicone

\begin{tabular}{|c|c|}
\hline \multicolumn{2}{|c|}{$117^{\circ} \mathrm{C}$} \\
\hline $\operatorname{Mass}$ & Int \\
\hline 12 & 8 \\
\hline 13 & 1 \\
\hline 14 & 51 \\
\hline 15 & 6 \\
\hline 16 & 27 \\
\hline 17 & $4 ?$ \\
\hline 18 & 100 \\
\hline 25 & 1 \\
\hline 26 & 5 \\
\hline 27 & 17 \\
\hline 28 & 1000 \\
\hline 32 & 45 \\
\hline 37 & 2 \\
\hline 38 & 4 \\
\hline 39 & 19 \\
\hline 40 & 13 \\
\hline 41 & 23 \\
\hline 42 & 15 \\
\hline 43 & 20 \\
\hline 44 & 31 \\
\hline 45 & 17 \\
\hline 50 & 5 \\
\hline 51. & 9 \\
\hline 52 & 5 \\
\hline 53 & 5 \\
\hline 5 . & 4 \\
\hline 55 & 17 \\
\hline 56 & 12 \\
\hline 57 & 27 \\
\hline 70 & 10 \\
\hline 77 & 21 \\
\hline 91 & 33 \\
\hline 107 & 13 \\
\hline
\end{tabular}

\begin{tabular}{|c|c|}
\hline \multicolumn{2}{|c|}{$230^{\circ} \mathrm{C}$} \\
\hline vass & In: \\
\hline 12 & 3 \\
\hline 13 & 1 \\
\hline 14 & 9 \\
\hline 15 & 12 \\
\hline 16 & 10 \\
\hline 17 & 28 \\
\hline 18 & $10 n$ \\
\hline 26 & 6 \\
\hline 27 & 18 \\
\hline 29 & 59 \\
\hline 29 & 15 \\
\hline 30 & 3 \\
\hline 32 & 5 \\
\hline 32 & 7 \\
\hline 97 & 3 \\
\hline 39 & 7 \\
\hline 30 & 22 \\
\hline 40 & $\mathrm{~g}$ \\
\hline 1 & 3 \\
\hline 4 & 11 \\
\hline 婊 & 25 \\
\hline 4 & $1 \%$ \\
\hline 45 & 95 \\
\hline 50 & 9 \\
\hline 51 & 12 \\
\hline 5 & A \\
\hline 55 & 1 \\
\hline 57 & 1 \\
\hline 39 & 2 \\
\hline 6 & 7 \\
\hline 64 & 7 \\
\hline 78 & 29 \\
\hline$t_{91}$ & 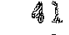 \\
\hline 07 & 1 \\
\hline
\end{tabular}

\begin{tabular}{|c|c|}
\hline \multicolumn{2}{|c|}{$360^{\circ} \mathrm{C}$} \\
\hline & $\pm n$ \\
\hline 12 & 2 \\
\hline 13 & $i$ \\
\hline i 4 & 5 \\
\hline 15 & 17 \\
\hline 26 & 7 \\
\hline 37 & 5 \\
\hline I里 & 15 \\
\hline 19 & 竞 \\
\hline 25 & 2 \\
\hline 28 & 24 \\
\hline $2 ?$ & 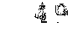 \\
\hline 29 & 43 \\
\hline 29 & 35 \\
\hline 31 & 3 \\
\hline$\frac{32}{2}$ & $\dot{b}$ \\
\hline 37 & 26 \\
\hline 38 & 30 \\
\hline 39 & ba \\
\hline 41 & in \\
\hline 42 & 55 \\
\hline 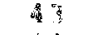 & 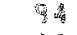 \\
\hline 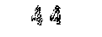 & 裔 \\
\hline 45 & $\frac{2}{23}$ \\
\hline 4 解 & 10 \\
\hline 49 & Ga \\
\hline 37 & 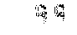 \\
\hline 52 & 72 \\
\hline 52 & $1 \%$ \\
\hline 59 & 47 \\
\hline 54 & 数 \\
\hline 55 & 47 \\
\hline 62 & 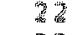 \\
\hline 49 & 2 \\
\hline 6 & 27 \\
\hline 79 & 3 \\
\hline 11 & 27 \\
\hline$\frac{7}{8}$ & 23 \\
\hline 77 & 290 \\
\hline 76 & 15 \\
\hline 99 & 16 \\
\hline an & I\% \\
\hline 91 & 20 \\
\hline 82 & $2 \%$ \\
\hline 91 & 15 \\
\hline 96 & 2 \\
\hline $10 \%$ & 3 \\
\hline 124 & 1 \\
\hline 117 & 2 \\
\hline 127 & 2 \\
\hline 141 & ¿. \\
\hline 153 & 2 \\
\hline
\end{tabular}


Table B-4: BRF-50201 silicone

\begin{tabular}{|c|c|}
\hline \multicolumn{2}{|c|}{$120^{\circ} \mathrm{C}$} \\
\hline dass & $\operatorname{Int}$ \\
\hline 12 & 1 \\
\hline 16 & 4 \\
\hline 15 & $\mathbb{1}$ \\
\hline 16 & 2 \\
\hline 17 & 2 \\
\hline 18 & 6 \\
\hline 26 & 1 \\
\hline 27 & 6 \\
\hline 28 & 36 \\
\hline 29 & 8 \\
\hline 30 & 1 \\
\hline 31 & 1 \\
\hline 32 & 5 \\
\hline 37 & 1 \\
\hline 33 & 3 \\
\hline 39 & 11 \\
\hline 40 & 5 \\
\hline$\Delta 1$ & 11 \\
\hline 42 & 5 \\
\hline 43 & I1. \\
\hline 45 & 3 \\
\hline $4 \sqrt{3}$ & 2 \\
\hline 50 & 4 \\
\hline 51 & 7 \\
\hline 52 & 3 \\
\hline 55 & 8 \\
\hline 56 & 8 \\
\hline 57. & 11 \\
\hline 60 & 1 \\
\hline 61 & 3 \\
\hline 62 & 7 \\
\hline 67 & 9 \\
\hline 65 & 3 \\
\hline 69 & 5 \\
\hline 69 & 5 \\
\hline $7 n$ & 6 \\
\hline 77 & 3 \\
\hline 8 & 蛊 \\
\hline 息意 & $\underline{M}$ \\
\hline 38 & 3 \\
\hline 91 & 100 \\
\hline 96 & 离 \\
\hline 104 & 3 \\
\hline 110 & 3 \\
\hline 118 & 2 \\
\hline 125 & 2 \\
\hline 132 & 1 \\
\hline 139 & 2 \\
\hline 1. 12 & 1 \\
\hline 151 & 1 \\
\hline 153 & 1 \\
\hline 155 & 2 \\
\hline 192 & 1 \\
\hline 206 & 1 \\
\hline 250 & 1 \\
\hline
\end{tabular}

\begin{tabular}{|c|c|}
\hline \multicolumn{2}{|c|}{3500} \\
\hline Mass & Int \\
\hline 12 & $\mathbb{1}$ \\
\hline 13 & $i$ \\
\hline 14 & I \\
\hline 15 & 7 \\
\hline It & 3 \\
\hline 17 & I \\
\hline 18 & 2 \\
\hline 25 & $\overrightarrow{1}$ \\
\hline 26 & 10 \\
\hline 27 & 13 \\
\hline 28 & 0 \\
\hline 29 & 1 \\
\hline $3 n$ & I \\
\hline 31 & : \\
\hline 32 & 1 \\
\hline 36 & 1 \\
\hline 37 & 7 \\
\hline 39 & $1 ?$ \\
\hline 39 & $2 \pi$ \\
\hline 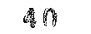 & n \\
\hline 4 & 4 \\
\hline 42 & 1 \\
\hline 43 & 2 \\
\hline 每息 & 1 \\
\hline 45 & 5 \\
\hline $5 \pi$ & 72 \\
\hline 51 & 参调 \\
\hline 52 & 32 \\
\hline 5 & 3 \\
\hline 55 & 2 \\
\hline 56 & 1 \\
\hline 62 & $a$ \\
\hline 66 & 8 \\
\hline 7 & 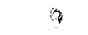 \\
\hline 74 & 7 \\
\hline 77 & lon \\
\hline 91 & 3 \\
\hline 95 & 1 \\
\hline 104 & 1. \\
\hline 116 & 1 \\
\hline 127 & 0.5 \\
\hline 131 & $\theta .5$ \\
\hline 140 & 0.5 \\
\hline 153 & 0.5 \\
\hline 176 & 0.5 \\
\hline 190 & 1 \\
\hline 109 & 78.5 \\
\hline 206 & 3 \\
\hline 269 & 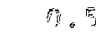 \\
\hline 290 & 1 \\
\hline
\end{tabular}


Table B-5: CS-4202 Silicone

\begin{tabular}{lr}
\multicolumn{2}{c}{$202^{\circ} \mathrm{C}$} \\
\cline { 1 - 1 } Mass & Int \\
\hline 12 & 3 \\
13 & 1 \\
14 & 12 \\
15 & 3 \\
16 & 7 \\
17 & 5 \\
18 & 12 \\
26 & 3 \\
27 & 10 \\
28 & 100 \\
29 & 19 \\
32 & 14 \\
37 & 2 \\
38 & 3 \\
39 & 12 \\
40 & 7 \\
41 & 19 \\
42 & 10 \\
43 & 14 \\
44 & 8 \\
45 & 8 \\
50 & 5 \\
51 & 7 \\
52 & 5 \\
53 & 3 \\
55 & 14 \\
56 & 8 \\
57 & 10 \\
62 & 2 \\
64 & 1 \\
67 & 3 \\
69 & 7 \\
70 & 5 \\
71 & 3 \\
72 & 2 \\
73 & 2 \\
77 & 37
\end{tabular}

\begin{tabular}{|c|c|}
\hline & \\
\hline Mass & Int \\
\hline 12 & 1 \\
\hline 13 & 1 \\
\hline 14 & 2 \\
\hline 15 & 6 \\
\hline 16 & 2 \\
\hline 17 & 0.5 \\
\hline 18 & I \\
\hline 25 & 1 \\
\hline 26 & 10 \\
\hline 27 & 14 \\
\hline 28 & 13 \\
\hline 29 & 2 \\
\hline 36 & 1 \\
\hline 37 & 9 \\
\hline 38 & 15 \\
\hline 39 & 36 \\
\hline 40 & 11 \\
\hline 41 & 21 \\
\hline 42 & 16 \\
\hline 49 & 5 \\
\hline 50 & 34 \\
\hline 51 & 46 \\
\hline 52 & 36 \\
\hline 62 & 10 \\
\hline 66 & de \\
\hline 73 & 10 \\
\hline 77 & 100 \\
\hline 81 & 3 \\
\hline 90 & 3 \\
\hline 103 & 2 \\
\hline 114 & 1 \\
\hline 117 & 1 \\
\hline 128 & 1 \\
\hline 142 & 0.5 \\
\hline 168 & 0.5 \\
\hline 178 & 0.5 \\
\hline 86 & 1 \\
\hline
\end{tabular}




\section{Distribution:}

B. I. Sadier, D8IA-1, BRC

C. H. Smith, D8IA-2, BKC

1554 O. Milton

2330 E. H. Barsis

2360 T. I. Workman

Attn: 2363 H. M. Barnett

4310 C. C. Burks

$$
2362 \text { G. I. Cessac }
$$

4320 G. J. Bildebrandt

4330 E. E. Tves

430 H.

4360 J. H. Hood

445 E. A. Salazar

5154 Q. M. Biefeld (5)

3800 R. S. Claassen

ittn: 5820 R. E. Whan

5830 M. J. Davis

5810 R. G. Repler

Attn: 5811 L. A. Harrah

5811 C.Arnols

5811 R. H. Clough

5811 虾。 Truji10

$58.4 F, p \cdot$ Gerste

5813 o. Curro

Attr: 5814 R. R. Rirschbuehler

5815 R. T.Johnson (5)

5815 J.H. Litr

5815 F. Francis

8110 J. Barmam

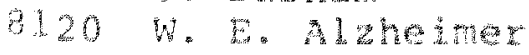

8150 J. I. W. Wh

8160 R. D. Co2ine

8310 D. M. Sehnster

8320 R. I. Rinne

3141 T. Exickson (5)

3151 W. L. Garner (3)

$3154-3$ C. Dalin (25)

(For DOE/TIC) (unimited release) 